\title{
Influence of a nonionic surfactant on curcumin delivery of nanocellulose reinforced chitosan hydrogel
}

Article

Accepted Version

Creative Commons: Attribution-Noncommercial-No Derivative Works 4.0

Sampath Udeni Gunathilake, T. M., Ching, Y. C., Chuah, C. H., Illias, H. A., Ching, K. Y., Singh, R. and Liou, N.-S. (2018) Influence of a nonionic surfactant on curcumin delivery of nanocellulose reinforced chitosan hydrogel. International Journal of Biological Macromolecules, 118 (A). pp. 1055-1064. ISSN 0141-8130 doi:

https://doi.org/10.1016/j.ijbiomac.2018.06.147 Available at https://centaur.reading.ac.uk/78348/

It is advisable to refer to the publisher's version if you intend to cite from the work. See Guidance on citing.

To link to this article DOI: http://dx.doi.org/10.1016/j.ijbiomac.2018.06.147

Publisher: Elsevier

All outputs in CentAUR are protected by Intellectual Property Rights law, including copyright law. Copyright and IPR is retained by the creators or other copyright holders. Terms and conditions for use of this material are defined in the End User Agreement. 


\section{CentAUR}

Central Archive at the University of Reading

Reading's research outputs online 


\section{Influence of a nonionic surfactant on curcumin delivery of nanocellulose reinforced chitosan hydrogel}

Article

Accepted Version

Gunathilake, T.M.S.U., Ching, Y.C., Chuah, C.H., Illias, H.A., Ching, K. Y., Singh, R. and Liou, N.-S. (2018) Influence of a nonionic surfactant on curcumin delivery of nanocellulose reinforced chitosan hydrogel. International Journal of Biological Macromolecules, 118. pp. 1055-1064. ISSN 01418130 doi: https://doi.org/10.1016/j.ijbiomac.2018.06.147 Available at https://centaur.reading.ac.uk/102063/

It is advisable to refer to the publisher's version if you intend to cite from the work. See Guidance on citing.

To link to this article DOI: http://dx.doi.org/10.1016/j.ijbiomac.2018.06.147

Publisher: Elsevier

All outputs in CentAUR are protected by Intellectual Property Rights law, including copyright law. Copyright and IPR is retained by the creators or other copyright holders. Terms and conditions for use of this material are defined in the End User Agreement. 


\section{CentAUR}

Central Archive at the University of Reading

Reading's research outputs online 


\author{
1 Influence of a nonionic surfactant on curcumin delivery of nanocellulose reinforced \\ 2 chitosan hydrogel \\ Thennakoon M. Sampath Udeni Gunathilakea, Yern Chee Ching ${ }^{\mathrm{a}}$, Cheng Hock Chuah ${ }^{\mathrm{b}}$, Hazlee Azil Illias ${ }^{\mathrm{c}}$ \\ Kuan Yong Ching ${ }^{d}$, Ramesh Singh ${ }^{e}$, Liou Nai-Shang ${ }^{f}$ \\ aDepartment of Chemical Engineering, Faculty of Engineering, University of Malaya, 50603 Kuala Lumpur, \\ Malaysiab \\ bepartment of Chemistry, Faculty of Science, University of Malaya, 50603 Kuala Lumpur, Malaysia \\ 'University of Reading Malaysia, Persiaran Graduan, Kota Ilmu, Educity, 79200 Iskandar Puteri, Johor, Malaysia \\ ${ }^{\mathrm{d} D e p a r t m e n t ~ o f ~ E l e c t r i c a l ~ E n g i n e e r i n g, ~ F a c u l t y ~ o f ~ E n g i n e e r i n g, ~ U n i v e r s i t y ~ o f ~ M a l a y a, ~} 50603$ Kuala Lumpur, \\ Malaysia \\ ${ }^{e}$ Department of Mechanical Engineering, Faculty of Engineering, University of Malaya, 50603 Kuala Lumpur, \\ Malaysia \\ fDepartment of Mechanical Engineering, Southern Taiwan University of Science and Technology, 710 Tainan City, \\ Taiwan, ROC
}

18

\title{
Abstract
}

Nanocellulose reinforced chitosan hydrogel was synthesized using chemical crosslinking method for the delivery of curcumin which is a poorly water-soluble drug. Curcumin extracted from the dried rhizomes of Curcuma longa was incorporated to the hydrogel via in situ loading method. A nonionic surfactant (Tween 20) was incorporated into the hydrogel to improve the solubility of curcumin. After the gas foaming process, hydrogel showed large interconnected pore structures. The release studies in gastric medium showed that the cumulative release of curcumin increased from $0.21 \% \pm 0.02 \%$ to $54.85 \% \pm 0.77 \%$ with the increasing of Tween 20 concentration from $0 \%$ to $30 \%(\mathrm{w} / \mathrm{v})$ after $7.5 \mathrm{~h}$. However, the entrapment efficiency percentage decreased with the addition of Tween 20. The gas foamed hydrogel showed higher initial burst release within the first 120 minutes compared to hydrogel formed at atmospheric condition. The solubility of curcumin would increase to $3.014 \pm 0.041 \mathrm{mg} / \mathrm{mL}$ when the Tween 20 concentration increased to $3.2 \%(\mathrm{w} / \mathrm{v})$ in simulated gastric medium. UV-visible spectra revealed that the drug retained its chemical activity after in vitro release. From these findings, it is believed that the nonionic 
32 surfactant incorporated chitosan/nanocellulose hydrogel can provide a platform to overcome

33 current problems associated with curcumin delivery.

34 Key words: Nanocellulose, chitosan, hydrogel, curcumin, Tween 20

37 1. Introduction

38 Curcumin is a lipophilic polyphenol compound which is derived from rhizomes of Curcuma 39 longa. Curcumin is usually a mixture of three curcuminoids (curcumin, demethocycurcumin, and 40 bisdemethoxycurcumin) and volatile oil [1]. Among all former studies on antibacterial activity of 41 curcumin, the most promising result showed is its effectiveness in against Helicobacter pylori 42 [2]. H. pylori is a microaerophilic bacterium which lives in the sticky mucus that lines 43 the stomach and it has attracted great attention as a main cause of peptic ulcer disease. 44 International agency for research on cancer has defined $H$. pylori as a group I carcinogenic agent 45 of human gastric cancer [3]. Recent studies on the inhibition of H. pylori using curcumin by 46 Mahady, Pendland, Yun and Lu [4] showed that both of the curcumin and methanolic extract of 47 turmeric rhizome has inhibited the growth of 19 different strains of $H$. pylori. Furthermore, De, 48 Kundu, Swarnakar, Ramamurthy, Chowdhury, Nair and Mukhopadhyay [3] mentioned that the 49 minimum inhibitory concentration of curcumin for $23 \%$ strains of $H$. pylori was about 10 $50 \mu \mathrm{g} / \mathrm{mL}$ and for $58 \%$ strains, it was $15 \mu \mathrm{g} / \mathrm{mL}$. Sometimes antibiotics are likely to be associated 51 with adverse side effects on the host such as allergic reactions, hypersensitivity and immune52 suppression. Therefore, there is an increasing demand to develop an alternative antimicrobial 53 drugs using medicinal plants for the treatments of infectious diseases [5]. 
54 Although curcumin exerts various biological effects, its limited aqueous solubility and rapid 55 presystemic metabolism has restricted its bioavailability. Therefore, the advanced drug delivery 56 systems like nanoparticles, liposomes, micellar formulations, cyclodextrin inclusion complexes, 57 microemulsions and different hydrogel based delivery systems have been developed to 58 circumvent their bioavailability issues [6-8]. Due to the variations on $\mathrm{pH}$ along the 59 gastrointestinal tract, the stimuli responsive (e.g.: $\mathrm{pH}$ sensitive) hydrogels have been used to 60 deliver various types of drugs to the different locations of the gastro intestinal tract [6-8]. In this 61 study, nanocellulose reinforced chitosan hydrogel was used as a carrier for drug delivery of 62 curcumin. From our previous study [9-11], we observed an improvement of mechanical 63 properties of the biopolymer based composite and hydrogel with physical reinforcement of 64 nanocellulose into the biopolymer matrix. Further, it showed that the swelling characteristics of 65 the hydrogel has improved with the addition of low concentrations of nanocellulose. The system 66 has also exerted the highest swelling properties in acidic medium [10]. It is also observed that the 67 chitosan hydrogel reinforced with $0.5 \%$ CNC has successfully achieved the highest swelling 68 properties and cumulative release of curcumin $[8,10]$. Therefore, in this study, $0.5 \%$ CNC69 chitosan hydrogel formulation was selected for further improvement of drug delivery properties 70 of the hydrogel. Previous results $[8,10]$ also showed that the percentage of curcumin 71 encapsulation and the amount of curcumin release increased in the gas foam hydrogel (due to the 72 formation of large interconnected pore structures). However, poor solubility of curcumin has 73 caused less concentrations of released drug in simulated gastric medium [8]. Therefore, a 74 nonionic surfactant (Tween 20) has been incorporated into the hydrogel as a solubilizing agent 75 for curcumin in this study. 
76 Surfactants can improve the solubility of some poorly soluble drugs. Tween surfactants contain

77 hydrophilic ethylene glycol head and a hydrophobic alkyl chain [12]. The commonly used

78 Tween are Tween 20, 40, 60 and 80. They possess same hydrophilic group with different length

79 of alkyl chains. The alkyl chain length will influence the hydrophile-lipophile balance (HLB)

80 value of the surfactant, which in turn directly influences the entrapment efficiency of the drug

81 [13]. Low HLB value corresponds to high hydrophobicity. Higher HLB value indicates the

82 more water soluble the surfactant [14]. Tween 20 with HLB value of 16.7 is more hydrophilic in

83 nature compared to other Tween surfactants [15]. Ratanajiajaroen, Watthanaphanit, Tamura,

84 Tokura and Rujiravanit [16] reported that the addition of $2 \%(\mathrm{v} / \mathrm{v})$ of Tween 20 has increased the

85 solubility of curcumin from $11 \mathrm{ng} / \mathrm{mL}$ to $0.767 \mathrm{mg} / \mathrm{mL}$ in acetate buffer (pH 5.5). In addition,

86 they obtained higher release rate of curcumin from chitin beads as the amount of Tween 20

87 increased. O’Toole, Henderson, Soucy, Fasciotto, Hoblitzell, Keynton, Ehringer and Gobin [17]

88 observed that the curcumin can be released completely from the submicrometer spray-dried

89 chitosan/Tween 20 particles in both $1 \%$ acetic acid and phosphate buffered saline solutions over

90 a $2 \mathrm{~h}$ period. Furthermore, the research works by Petchsomrit, Sermkaew and Wiwattanapatapee

91 [18] also reported that the percentage of curcumin release increased with increasing the Tween

9280 concentration in oil entrapped alginate beads. Their results showed that the cumulative drug

93 release increased up to $70 \%$ with the incorporation of $25 \%(\mathrm{w} / \mathrm{v})$ of Tween 80 .

94 Previous cytotoxicity studies revealed that nonionic surfactant such as Tween has lower toxic

95 effect than cationic, anionic and amphoteric ones [19]. Due to its less cytotoxicity properties, the

96 nonionic surfactant was selected for this study. Besides that, surfactants have a profound effect

97 on the release rate of the drug from the encapsulated matrix. Using proper concentration of

98 surfactant and a suitable HLB value, the cumulative release and rate of release of the drug can be 
99 controlled. According to the previous studies, the surfactants with lower HLB values such as 100 Tween 80 would cause lower release rates of hydrophobic drugs. This is because the surfactants 101 having lower HLB values are more lipophilic and less water soluble. But with higher HLB 102 values, hydrophobic drug release rate will increase as these surfactants are more hydrophilic and 103 water soluble [20]. Tween 20 has a high HLB value of 16.7 and this will help to improve the 104 release of hydrophobic drug to a desired level. Tween 80 had been successfully applied in many 105 hydrophobic drug delivery systems [21-25]. However, the investigations on polysorbate-chitosan 106 association by Picone and Cunha [26] has shown that the longer hydrophobic polysorbate tail 107 length of Tween 80 has made it difficult to form homogeneous association with chitosan. Their 108 further investigations had found that the shorter hydrophobic tail length of Tween 20 was more 109 appropriated to form mixed surfactant-chitosan polymer systems. So, Tween 20 which is a less 110 cytotoxic, nonionic, with shorter hydrophobic tail length surfactant was used to improve the drug 111 release of curcumin from nanocellulose reinforced chitosan hydrogel matrix in this study.

112 The objective of this study was to improve the bioavailability of less water-soluble curcumin by 113 incorporating a nonionic surfactant (Tween 20) to nanocellulose reinforced chitosan hydrogel. 114 Curcumin extracted from dried rhizomes of Curcuma longa and Tween 20 was incorporated to 115 the hydrogel via in situ loading method. From our previous study, a large extent of chitosan 116 matrix swelling was found to occur in acidic medium [10]. Therefore, the drug molecules are 117 expected to diffuse extensively through the swollen gel into the exterior medium at gastric $\mathrm{pH}$ 118 levels. Nonionic surfactant will further facilitate dissolution of the drug by partitioning the drug 119 into the aqueous phase of gastric fluid. Based on the results of this study, it is expected that the 120 nanocellulose reinforced chitosan hydrogel/Tween 20 drug delivery system will provide a 
121 platform to overcome poor bioavailability of curcumin to yield its broad range of therapeutic 122 benefits.

\section{2. Materials and Methods}

$124 \quad$ 2.1. Materials

125 Chitosan with medium molecular weight (viscosity $200-500 \mathrm{cP}, 0.5 \%$ acetic acid at $20{ }^{\circ} \mathrm{C}$ ), 126 acetic acid glacial grade AR, sodium chloride, hydrochloric acid, methanol and sulfuric acid 127 were purchased from Friendemann Schmidt Chemicals (Parkwood, Australia). The drug 128 curcumin was provided by HIMEDIA laboratories Pvt Ltd. (Mumbai, India). Glutaraldehyde $12925 \%$ (for crosslinking of chitosan) was obtained from Thermo Fisher Scientific Inc. (Victoria, 130 Australia). Microcrystalline cellulose, Tween 20 and phosphate-buffered saline were supplied by 131 R\&M chemicals (Essex, UK).

132 2.2. Research Methodology

133 2.2.1. Extraction of curcumin from turmeric

134 Curcumin was extracted from rhizomes of Curcuma longa following the method proposed 135 elsewhere [5]. Dried rhizomes were crushed in a mortar and pestle. Crushed rhizomes were 136 soaked in methanol for 3 days and then filtered with Whatman filter paper (pore size $0.2 \mu \mathrm{m}$ ). 137 After that, filtrate was poured into a petri plate and the solvent was evaporated under vacuum 138 condition to obtain semi-dry oily mass.

\section{2.2.2. Preparation of curcumin loaded chitosan/nanocellulose/Tween20 hydrogel}

140 Cellulose nanocrystals (CNC) were prepared from microcrystalline cellulose by sulfuric acid 141 hydrolysis method reported in our previous study [10]. Chitosan was dissolved in 5\% (v/v) 
142 aqueous acetic acid solution at room temperature and left overnight in the shaker with the

\begin{tabular}{|c|c|c|c|c|c|}
\hline Formulation & $\begin{array}{l}\text { Chitosan } \\
(\mathrm{w} / \mathrm{v}) \%\end{array}$ & $\begin{array}{c}\text { Nanocellulose } \\
\text { (w/v) } \%\end{array}$ & $\begin{array}{l}\text { Tween } 20 \\
(\mathrm{w} / \mathrm{v}) \%\end{array}$ & $\begin{array}{c}\text { Glutaraldehyde } \\
\qquad(\mathrm{v} / \mathrm{v}) \%\end{array}$ & $\begin{array}{l}\text { Curcumin } \\
\text { (mg per } 2.5 \mathrm{~g} \text { of } \\
\text { hydrogel disc) }\end{array}$ \\
\hline $\mathrm{CH} / \mathrm{CNC} / \mathrm{TW}-0 \%$ & 2 & 0.5 & 0 & 0.2 & 1.5 \\
\hline $\mathrm{CH} / \mathrm{CNC} / \mathrm{TW}-5 \%$ & 2 & 0.5 & 5 & 0.2 & 1.5 \\
\hline $\mathrm{CH} / \mathrm{CNC} / \mathrm{TW}-10 \%$ & 2 & 0.5 & 10 & 0.2 & 1.5 \\
\hline $\mathrm{CH} / \mathrm{CNC} / \mathrm{TW}-15 \%$ & 2 & 0.5 & 15 & 0.2 & 1.5 \\
\hline $\mathrm{CH} / \mathrm{CNC} / \mathrm{TW}-20 \%$ & 2 & 0.5 & 20 & 0.2 & 1.5 \\
\hline $\mathrm{CH} / \mathrm{CNC} / \mathrm{TW}-25 \%$ & 2 & 0.5 & 25 & 0.2 & 1.5 \\
\hline $\mathrm{CH} / \mathrm{CNC} / \mathrm{TW}-30 \%$ & 2 & 0.5 & 30 & 0.2 & 1.5 \\
\hline
\end{tabular}

rotation rate of $250 \mathrm{rpm}$ and then filtered through the filter paper to remove any insoluble

144 matters. To prepare curcumin loaded chitosan/nanocellulose/Tween 20 hydrogel, nanocellulose,

145 extracted curcumin and Tween 20 were added to chitosan solution and stirred ( $250 \mathrm{rpm})$ for one

146 hour. After that glutaraldehyde was added and stirred $(350 \mathrm{rpm})$ for $1 \mathrm{~min}$ at room temperature.

147 The mixture was then poured into the mold and the hydrogel was allowed to solidify at room

148 temperature for $24 \mathrm{~h}$.

149 Table 1.

150 Table 1: Composition of curcumin entrapped chitosan/nanocellulose/Tween 20 hydrogel

151

2.2.3. $\mathrm{CO}_{2}$ gas foaming of curcumin entrapped chitosan/nanocellulose/Tween 20 hydrogels 
153 After mixing the $\mathrm{CNC}$, drug, Tween 20 and crosslinker with chitosan solution as described 154 above, the mixture was poured into the mold and placed inside the gas foaming apparatus. Then 155 the apparatus was pressurized with $\mathrm{CO}_{2}$ to predetermined pressure (50 bar). The pressure was 156 maintained to allow for $\mathrm{CO}_{2}$ saturation and chitosan crosslinking for $48 \mathrm{~h}$. The system was then 157 depressurized at $1 \mathrm{bar} / \mathrm{min}$ to result in the generation of numerous gas bubbles which induce gas 158 foaming.

\subsection{Characterization}

\subsubsection{Characterization of curcumin}

164 UV-visible spectra of both curcumin (HIMEDIA Co.) and curcumin extracted from turmeric 165 were obtained by scanning the drug solutions within the range of 350-800 $\mathrm{nm}$ using UV-visible 166 spectrophotometer (Shimadzu, Kyoto, Japan). FTIR studies on curcumin purchased from 167 HIMEDIA Co. and curcumin extracted from turmeric, were carried out using PerkinElmer 168 spectrum 400 FTIR spectrometer over the range $3000-500 \mathrm{~cm}^{-1}$.

170 2.3.2. Characterization of the curcumin entrapped chitosan/nanocellulose/Tween 20 hydrogels

171 2.3.2.1. FTIR analysis 
172 FTIR studies of raw materials and various composition of hydrogel composites were carried out

173 by using PerkinElmer spectrum 400 FTIR spectrometer over the range $3000-500 \mathrm{~cm}^{-1}$.

$174 \quad$ 2.3.2.2. Morphology Studies

175 The morphology of the hydrogels was examined using field emission scanning electron 176 microscope (FE-SEM, SU8220). Hydrogels were freeze dried using freeze dryer to remove water 177 without disturbing the morphology. The hydrogels were then coated with platinum in order to 178 prevent the charging effects at an accelerating voltage of $5 \mathrm{kV}$.

179

$180 \quad$ 2.4. Drug delivery studies

181 2.4.1. Estimation procedure of curcumin by UV-Vis spectrophotometer

182 The absorption maxima $\left(\lambda_{\max }\right)$ for curcumin was determined by scanning the drug solution within 183 the range of $350-800 \mathrm{~nm}$ using UV-Vis spectrophotometer. It was found that the drug exhibited $184 \lambda_{\max }$ at $427 \mathrm{~nm}$ in both of the distilled water and simulated gastric medium as shown in Fig. 1a 185 and Fig. 2a, respectively. The concentration of curcumin extracted from turmeric was determined 186 by the standard calibration curve $\left(\lambda_{\max }\right.$ at $\left.427 \mathrm{~nm}\right)$ prepared using standard solutions of curcumin 187 (HIMEDIA Co).

188 The concentration of curcumin present in distilled water was determined from the calibration 189 curve (Fig. 1b) prepared from standard solutions of curcumin (HIMEDIA Co.), dissolved in 190 methanol and diluted by distilled water.

191 Fig. 1. a) UV-Vis absorbance spectrum of curcumin in distilled water and b) calibration curve of 192 curcumin. 
193 The concentration of curcumin present in simulated gastric fluid was determined from the 194 calibration curve (Fig. 2b) prepared from standard solutions of curcumin (HIMEDIA Co.), 195 dissolved in methanol and diluted by simulated gastric fluid [27, 28].

196 Fig. 2. a) UV-Vis absorbance spectrum of curcumin in simulated gastric medium and b) 197 calibration curve of curcumin.

198 2.4.2. Drug entrapment efficiency

199 Disc shape hydrogel $(1.80 \mathrm{~cm}$ diameter and $1.20 \mathrm{~cm}$ height $)$ was immersed in $30 \mathrm{~mL}$ ethanol for $20024 \mathrm{~h}$. Then, the solution was filtered and diluted suitably to measure the absorbance, from which 201 the concentration of drug was calculated using the standard calibration data. Each formulation 202 was analyzed in triplicate and average values were taken. The drug entrapment efficiency was 203 calculated based on the ratio of actual amount of drug present in the hydrogel to the initial 204 amount of drug contained in the hydrogel by using Equation (1).

205 Entrapment efficiency $=\frac{\text { Actual amount of curcumin in hydrogel }}{\text { Initial amount of curcumin contained in the hydrogel }}$

206 2.4.3. Drug release

207 In vitro drug release from hydrogel networks with different Tween 20 concentrations was 208 investigated in simulated gastric fluid (simulated gastric fluid was prepared by dissolving $2 \mathrm{~g}$ $209 \mathrm{NaCl}$ in $7.0 \mathrm{~mL} \mathrm{HCl}$ and water up to $1000 \mathrm{~mL}$ ) at $37^{\circ} \mathrm{C}$ [29]. In order to study the release, $3 \mathrm{~mL}$ 210 aliquot was withdrawn at predetermined time intervals and returned it back to the solution after 211 the analysis. The concentration of released curcumin was determined by the calibration curve 212 (Fig. 2b) prepared using the curcumin (HIMEDIA Co.) in simulated gastric fluid. The 213 experiments were performed triplicates and average values were taken. 


\subsubsection{Drug activity}

215 In drug delivery systems, the chemical and biological activity of drug after release into the body 216 is the most critical parameter. The drug activity of curcumin before loading and after release 217 could be studied by using UV-Vis spectrophotometer [30]. UV- visible spectra of pure drug and 218 the drug released from the hydrogel formed at atmospheric condition were obtained by scanning 219 the solutions within the range of 350-800 $\mathrm{nm}$ using UV-visible spectrophotometer. Drug activity 220 was determined through comparison between the spectra (the absorption maxima $\left(\lambda_{\max }\right)$ ) of pure 221 drug and released drug.

\subsection{Curcumin solubility studies}

223 To determine a saturated concentration of curcumin in simulated gastric fluid, an excess amount 224 of curcumin (extracted from turmeric) was added in to $30 \mathrm{~mL}$ of simulated gastric fluid with 225 different concentrations of Tween $20(0.8 \%, 1.6 \%, 2.4 \%, 3.2 \%, 4 \%, 5.6 \%(\mathrm{w} / \mathrm{v}))$. Then, the 226 mixtures were stirred $(350 \mathrm{rpm})$ using magnetic stirrer at $37^{\circ} \mathrm{C}$ for $12 \mathrm{~h}$. Samples were covered to 227 avoid exposition to the light. After that, the solutions were centrifuged at 10,000 rpm for $10 \mathrm{~min}$, 228 supernatant was decanted and the dissolved curcumin was determined using the standard 229 calibration curve prepared using the curcumin (HIMEDIA Co.) in simulated gastric fluid (Fig. $2302 b)$.

3. Results and discussion

\subsection{Characterization of curcumin}


233 As shown in Fig. 3, the UV-visible spectra of curcumin (HIMEDIA Co.) and curcumin extracted

234 from turmeric were obtained by scanning the drug solutions within the range of $350-800 \mathrm{~nm}$ 235 using UV-visible spectrophotometer.

236 Fig. 3. UV-visible spectra of curcumin extracted from turmeric powder and curcumin 237 (HIMEDIA Co.).

238 The UV- visible spectra of curcumin represent the transition between the electronic energy 239 levels. The maximum absorption wavelength of a compound is a measure of the difference 240 between energy levels of the orbitals concerned. An isolated double bond/lone pair produces 241 strong absorption maximum around $190 \mathrm{~nm}$, whereas the presence of conjugation decreases the 242 energy separation between orbitals and give rise to the absorption at longer wavelengths. In 243 organic solvents enolization of diketone of curcumin conjugates between the $\pi$-electron clouds of 244 the two vinylguaiacol parts leading to a common conjugated chromophore, resulted in decrease 245 in energy. As a result of low-energy $\pi-\pi^{*}$ excitation of that chromophore, curcumin in organic 246 solvents (primarily in methanol or ethanol) typically absorbs around $\sim 420 \mathrm{~nm}$ and appears in 247 yellow color [31].

248 The FTIR spectra of curcumin (HIMEDIA Co.) and curcumin derived from turmeric powder are 249 shown in Fig. 4. The differences in the $3100-3600 \mathrm{~cm}^{-1}$ range may be attributed to the $\mathrm{OH}$ 250 stretching of the methanol molecules adsorbed in the curcumin derived from turmeric powder 251 [32]. The appearance of strong peak at $1582 \mathrm{~cm}^{-1}$ and no peak at $1317 \mathrm{~cm}^{-1}$ in the derived 252 curcumin as well as various displacements of the peaks may be due to different interactions 253 between functional groups of curcumin. As shown in Fig. 5, the chemical composition of the 
254 extracted curcumin is a mixture of curcuminoids (curcumin, demethoxycurcumin and bis255 demethoxycurcumin).

Fig. 4. FTIR spectra of curcumin (HIMEDIA Co.) and curcumin derived from turmeric.

Fig. 5. Curcuminoids present in turmeric powder.

258 The IR spectrum of curcumin derived from turmeric is more similar to the IR spectrum of 259 crystalline curcumin derived from turmeric powder (extracted using actone/ethanol/methanol), 260 which was reported in previous studies [32, 33]. A broad peak at $3380 \mathrm{~cm}^{-1}$ indicates the 261 presence of $-\mathrm{OH}$ group. In the highest frequency region, phenolic vibrations of the curcumin has 262 theoretical frequency at $3595 \mathrm{~cm}^{-1}$, but in practice this band could be shifted downwards due to 263 the intramolecular and intermolecular hydrogen bonds [33, 34]. The appearance of bands with 264 low intensity in the region from $2700-3000 \mathrm{~cm}^{-1}$ can be attributed to the $\mathrm{C}-\mathrm{H}$ stretches [33]. The 265 highest frequency bands observed within $2700-3000 \mathrm{~cm}^{-1}$ region are assigned to the aromatic C $266 \square \mathrm{H}$ stretches, while the lower frequency bands are attributed to the methyl group motions [34]. 267 The peak at $1679 \mathrm{~cm}^{-1}$ appeared due to the $\mathrm{C}=\mathrm{O}$ vibrations [33]. The band at $1623 \mathrm{~cm}^{-1} \mathrm{can} \mathrm{be}$ 268 assigned to the $v(\mathrm{C}=\mathrm{C})$ of the benzene ring [35]. The strong peak at $1582 \mathrm{~cm}^{-1}$ has a 269 predominantly mixed $v(\mathrm{C}=\mathrm{C})$ and $v(\mathrm{C}=\mathrm{O})$ characteristic. The most prominent band in the IR 270 spectrum is at $1509 \mathrm{~cm}^{-1}$. This can be attributed to highly mixed vibrations $\left({ }^{v} \mathrm{C}=\mathrm{O},{ }^{\delta} \mathrm{CC}{ }^{10} \mathrm{C}\right.$, $\left.271{ }^{\delta} \mathrm{CC}=\mathrm{O}\right)[33]$. The peaks at $1430 \mathrm{~cm}^{-1}$ appeared due to the asymmetric angular deformation 272 vibrations of methyl groups [34]. The observed bands at $1377 \mathrm{~cm}^{-1}$ and $1207 \mathrm{~cm}^{-1}$ can be 273 attributed to $v(\mathrm{C}-\mathrm{O})$ and $\delta(\mathrm{C}=\mathrm{C}-\mathrm{H})$ of interring chain, respectively. One band and one shoulder at $2741270 / 1238 \mathrm{~cm}^{-1}$ and peak at $1167 \mathrm{~cm}^{-1}$ are attributed to the in-plane deformation vibrations of $275(\mathrm{CCH})$ of phenyl rings and skeletal in-plane deformations, respectively. A prominent band at 
$2761124 \mathrm{~cm}^{-1}$ is assigned also to the (C-O-C) vibrations [33]. The peak at $1031 \mathrm{~cm}^{-1}$ appeared due to 277 C-O stretching coupling with the adjacent C-C stretching vibrations [32]. The bands at $964 \mathrm{~cm}^{-1}$ 278 and $815 \mathrm{~cm}^{-1}$ assigned to the $v(\mathrm{C}-\mathrm{O})$ vibrations. The IR bands at $815 \mathrm{~cm}^{-1}$ and $720 \mathrm{~cm}^{-1}$ belongs 279 to the $v(\mathrm{C}-\mathrm{H})$ out of plane vibration of the aromatic ring [34]. In the range of $700-500 \mathrm{~cm}^{-1}$, we 280 could see deformation vibrations of both benzene rings and the out of plane vibrations of both $281 \mathrm{OH}$ groups, which are at $607 \mathrm{~cm}^{-1}$ and $546 \mathrm{~cm}^{-1}[33]$.

3.2. Characterization of curcumin entrapped chitosan/nanocellulose/Tween 20 hydrogels

\subsubsection{FTIR analysis}

287 Fig. 6 displays the FTIR spectra of curcumin (extracted), Tween 20, and curcumin/Tween 20 288 incorporated chitosan based hydrogel. From the spectrum of curcumin/Tween 20 incorporated 289 chitosan hydrogel, it can be seen that the bands corresponded to the functional groups of Tween 29020 are more prominent together with the bands assigned to the functional groups of the hydrogel.

291 The sharper peaks related to the functional groups of curcumin are super imposed by the broader 292 peaks of Tween 20 and chitosan hydrogel [35] (in the spectrum of curcumin/Tween 20 293 incorporated hydrogel). Also, the drug concentration loaded to the hydrogel is very low when 294 compared to Tween 20 concentration. Therefore, the peaks related to Tween 20 are more 295 prominent in the spectrum of curcumin/Tween 20 incorporated hydrogel. However, there are no 296 new peaks appeared in the spectrum of curcumin/Tween 20 incorporated hydrogel. 
297 Fig. 6. FTIR spectra of curcumin (extracted), Tween 20, nanocellulose reinforced chitosan 298 hydrogel and curcumin/Tween 20 incorporated hydrogel.

299 3.2.2. Morphology studies

300 The morphology of $0.5 \%$ CNC-chitosan hydrogels formed at atmospheric condition and high301 pressure conditions (50 bar) was examined using field emission scanning electron microscope. 302 The micrographs of the cross section of hydrogels are shown in Fig.7. The micrographs clearly 303 show the porous network of the gels. As shown in Fig. 7a, hydrogel formed at atmospheric 304 condition showed closed pore structures with around 100-300 $\mu \mathrm{m}$ pore size. After the gas 305 foaming, the pore size of the hydrogel significantly increased (more than 10-fold higher 306 compared to the hydrogel formed at atmospheric condition) with the formation of interconnected 307 pore network structures (Fig. 7b).

308 Fig. 7. Micrographs of a) hydrogel formed at atmospheric condition and b) gas foamed hydrogel

309 Skin layer formation and poor pore interconnectivity are common issues in porous fabrication 310 techniques. However, these can be overcome by fabrication of polymer matrices using gas 311 foaming method [37]. The porous structure is generated when the discontinuous dispersed gas 312 phase is removed from the continuous phase of polymer. These polymeric foams have low 313 kinetic stability due to the significant difference between the densities of the gas and liquid. The 314 liquid phase tends to move down while the gas tends to move upwards, which leads to the 315 formation of interconnected porous structure with highly porous top surface [38].

\section{$316 \quad 3.3$ Drug delivery studies}

\section{3.3.1. Entrapment efficiency}


The drug entrapment efficiency of the hydrogel with different concentrations of surfactant was

319 studied and the results are shown in Fig. 8. To form curcumin loaded hydrogel, $1.5 \mathrm{mg}$ of 320 curcumin was entrapped in $2.50 \mathrm{~g}$ of hydrogel (disc diameter $1.8 \mathrm{~cm}$ and height $1.2 \mathrm{~cm}$ ). The 321 hydrogel with $0 \%(\mathrm{w} / \mathrm{v})$ surfactant revealed the highest drug entrapment efficiency value of $92.09 \% \pm 0.15 \%$, whereas hydrogel containing 30\% (w/v) Tween 20 demonstrated the least value of $70.21 \% \pm 0.26 \%$. The percentage entrapment efficiency decreased significantly from $92.09 \% \pm 0.15 \%$ to $77.92 \% \pm 0.70 \%$ with the addition of $5 \%(\mathrm{w} / \mathrm{v})$ surfactant to the hydrogel. After that, it slightly decreased from $77.92 \% \pm 0.70 \%$ to $70.21 \% \pm 0.26 \%$ with increasing the surfactant concentration from $5 \%$ to $30 \%(\mathrm{w} / \mathrm{v})$.

327

Fig. 8. Entrapment efficiency of curcumin for gas foamed hydrogel and hydrogel formed at atmospheric condition.

Similar results were obtained by Petchsomrit, Sermkaew and Wiwattanapatapee [18] for oil 330 entrapped alginate bead formulation of curcumin. Tween 80 was used as the surfactant for their study and the entrapment efficiency of curcumin was found to decrease from $73.69 \% \pm$ $2.04 \%$ to $40.28 \% \pm 0.23 \%$ with increasing the Tween 80 content from $0 \%$ to $30 \%$. From the study of variability of (poly lactic-co-glycolic acid) PLGA nanoparticles quality of protein loaded PLGA nanoparticles by Plackett-Burman design, Rahman, Zidan, Habib and Khan [39] described that the decreasing of the entrapment efficiency with increasing the surfactant is 336 due to the fact that the higher concentration of the emulsifier increases the partition of the drug 337 from internal to external phase due to the increased solubility of the drug in the external phase. In 338 addition, the alkyl chain length influences the hydrophile-lipophile balance (HLB) value of the 339 surfactant, which in turn directly affects the drug entrapment efficiency [13]. Non-ionic 340 surfactants have hydrophilic and lipophilic properties and are characterized by its' hydrophile- 
341 lipophile balance values. Low HLB value corresponds to high hydrophobicity. The higher HLB 342 value the more water soluble the surfactant [40]. The lower the HLB of the surfactant the higher 343 will be the drug entrapment efficiency as in the case of niosomes prepared using Span 60 (HLB $344=4.7$ ), compared with Span 40 with a higher HLB of 6.7 [41-43]. The HLB value of Tween 20 345 is 16.7. The higher HLB value represents higher hydrophilic property. According to Dinarvand, 346 Moghadam, Sheikhi and Atyabi [44], the higher internal aqueous volume may increase the 347 volume of water droplets in the hydrophobic phase. This will promote more contact and 348 exchange (drug loss) to the external water phase. Polymer phase acts as a diffusion barrier 349 against movement of drug molecules between the internal and external aqueous phases; the 350 thickness of this layer decreases when the internal aqueous volume is increased. This may lead to 351 the reduction of drug entrapment efficiency.

352 In this study, we have compared the drug delivery behavior of the gas foamed hydrogel with the 353 hydrogel prepared at atmospheric condition. As can be seen from the Fig. 8, the entrapment 354 efficiency of curcumin in gas foamed hydrogel is slightly lower than that of the hydrogel formed 355 at atmospheric condition. This result is different compared to our previous study [8], which has 356 reported that the gas foamed hydrogel has higher drug entrapment efficiency compared to 357 hydrogel formed in atmospheric condition. This may be caused by the different drug loading 358 methods that have been applied in these two different studies. In previous study [8], the drug 359 was encapsulated by post-loading method. However, in this study we are applying in situ 360 loading method for the comparative study between the hydrogels prepared under gas foamed 361 and atmospheric condition. In situ loading method is used in this study to incorporate both of 362 the surfactant and the drug to the hydrogel matrix. This in situ loading method does not 363 perform the same as the previous post-loading method [44]. From the studies on the effects of 
364 different drug loading methods on drug delivery, Wong and Dodou [45] reported that the drug is 365 embedded within polymeric network when in situ loaded, instead of being deposited in 366 microporous spaces of the hydrogel when post loaded method was applied. As can be seen 367 from Fig. 7, the hydrogel prepared at atmospheric condition composed of small pore 368 structures when compared to the gas foamed hydrogel. The decrease of pore size of the 369 hydrogel simply correlated with the higher hydrogel density, which contributing to more 370 embedded drug in the hydrogel matrix and higher encapsulation efficiency. Therefore, in this 371 study, the hydrogel prepared at atmospheric condition showed higher encapsulation efficiency 372 compared to gas foamed hydrogel. Petchsomrit, Sermkaew and Wiwattanapatapee [6] also 373 reported that the higher hydrogel density contributed to the increase of curcumin content on in 374 situ drug loaded, alginate-based composite sponge.

375 From the comparison between post loaded formulations from our previous study [8] and in situ 376 loaded formulations used in this study, it is found that the in situ loading method provides better 377 drug entrapment efficiency within hydrogel network for all the hydrogel prepared under gas 378 foamed and atmospheric condition due to the specific interactions between polymer and drug 379 molecules [45].

\subsubsection{Drug release}

382 The oral bioavailability of a drug relies upon on its solubility and/or dissolution rate, and 383 dissolution can be the rate determining step for the onset of drug action. Hence there are 384 numerous approaches available and reported in literature to enhance dissolution and drug 385 bioavailability of poorly water-soluble drugs [7-10, 46-47]. The use of surfactant to improve the 
solubility of hydrophobic/lipophilic drugs is a common practice in the industry and it has been extensively studied by many researchers [46-47]. In this study, curcumin and Tween 20 were 388 incorporated into hydrogel matrix via in-situ loading method to allow hydrogel network formulation and drug encapsulation are accomplished simultaneously.

Fig. 9. Curcumin release from the hydrogels containing different concentrations of Tween 20 .

391 The hydrogel discs $(1.2 \mathrm{~cm}$ height and $1.8 \mathrm{~cm}$ diameter $)$ containing $1.5 \mathrm{mg}$ of drug with different concentrations of Tween $20(5 \%, 10 \%, 15 \%, 20 \%, 25 \%$ and $30 \%(\mathrm{w} / \mathrm{v}))$ were immersed in simulated gastric fluid and drug release was monitored over a period of $7.5 \mathrm{~h}$. Since the solubility 394 of curcumin is very low [46], a large volume of the releasing medium was used to maintain a 395 good sink condition [47]. As can be seen in Fig. 9, the cumulative release of curcumin increased 396 from $0.21 \% \pm 0.02 \%$ to $54.85 \% \pm 0.77 \%$ with increasing the Tween 20 concentration from $0 \%$ to $30 \%(\mathrm{w} / \mathrm{v})$, after $7.5 \mathrm{~h}$ immersion. Release studies in the presence of Tween 20 show a burst 398 release profile for curcumin, up to $20 \%$ of curcumin released in the first 60 min of the 399 experiment. As shown in Fig. 9, with the increase of Tween 20 concentration from 5-30\% (w/v), 400 at a fixed drug concentration, the amount of drug release increased from $31.82 \% \pm 0.75 \%$ to $40154.85 \% \pm 0.77 \%$. This is almost 1.7 -fold increase after $7.5 \mathrm{~h}$. During the time of monitoring, the 402 formulations containing lower amount of Tween 20 produced an incomplete solubilization of 403 curcumin, whereas complete solubilization showed at high concentration of Tween 20. 404 Therefore, larger amount of surfactant produced a higher drug release. Ratanajiajaroen and 405 Ohshima [7] showed that the solubility of curcumin increased from $11 \mathrm{mg} / \mathrm{mL}$ to $0.767 \mathrm{mg} / \mathrm{mL}$ 406 with Tween 20 , at a concentration of $2 \%(\mathrm{v} / \mathrm{v})$ in acetate buffer $(\mathrm{pH} 5.5)$. In addition, they found 407 that the drug release rate increased from chitin beads as the Tween 20 concentration increased. 408 O'Toole, Henderson, Soucy, Fasciotto, Hoblitzell, Keynton, Ehringer and Gobin [17] 
investigated that the curcumin saturation point increased linearly with Tween 20 concentration throughout the range used in their experiments with an upper limit of $294 \mu \mathrm{M}$ curcumin with 411 $0.05 \%(\mathrm{w} / \mathrm{v})$ Tween 20 . Further, they reported that curcumin can be released completely from the 412 submicrometer spray-dried chitosan/Tween 20 particles in both $1 \%$ acetic acid and phosphate 413 buffered saline solutions over a $2 \mathrm{~h}$ period.

414 Moreover, in terms of therapeutic applications for abdominal disorders, the doses of curcumin up 415 to the healing levels should also been concerned. Considering the strong association of H. pylori 416 and gastric cancer the authors of the study by Mahady, Pendland, Yun and Lu [4] showed that 417 both curcumin and methanolic extract of turmeric rhizome inhibited the growth of 19 different 418 strains of $H$. pylori. They reported that curcumin inhibited the growth of all the H.pylori strains 419 by $100 \%$ at a concentration of $12.5 \mu \mathrm{g} / \mathrm{mL}$ with a minimum inhibitory concentration from $6.25-$ $42012.5 \mu \mathrm{g} / \mathrm{mL}$. De, Kundu, Swarnakar, Ramamurthy, Chowdhury, Nair and Mukhopadhyay [3] 421 investigated that the minimum inhibitory concentration of curcumin for H.pylori strains ranged 422 from $5 \mu \mathrm{g} / \mathrm{mL}$ to $50 \mu \mathrm{g} / \mathrm{mL}$, and the majority of the strains $(81 \%)$ showed a minimum inhibitory 423 concentration of either $10 \mu \mathrm{g} / \mathrm{mL}(23 \%)$ or $15 \mu \mathrm{g} / \mathrm{mL}(58 \%)$. In addition, curcumin is able to 424 suppress the proliferation and survival of cancer cells by directly or indirectly binding to various 425 cellular molecular targets [48]. Liu, Xiang, Wu and Wang [49] reported that curcumin inhibited 426 the growth of gastric cancer cells in a concentration and a time-dependent manner. Their studies 427 showed that as compared to untreated cancer cells, the cell proliferation was significantly 428 inhibited in the curcumin treated samples after $48 \mathrm{~h}$ of treatment with $50 \mu \mathrm{M}$ curcumin. In our 429 study, the maximum concentration of curcumin released in the simulated gastric fluid was 3.98 $430 \mu \mathrm{g} / \mathrm{mL}$ after $7.5 \mathrm{~h}$. Even so, we found that the drug release of the hydrogel increased $(\geq 10$ $431 \mu \mathrm{g} / \mathrm{mL}$ ) with increasing the initial concentration of the drug which incorporated to the hydrogel 
432 (for same Tween 20 concentration). However, with increasing the initial amount of drug, the 433 percentage release of drug dramatically decreased during the period of monitoring. Therefore, $434 \quad 1.5 \mathrm{mg}$ of drug per hydrogel disc $(1.2 \mathrm{~cm}$ height and $1.8 \mathrm{~cm}$ diameter $)$ was used for the 435 encapsulation in this study. However, the initial drug loading amount to the hydrogel can be

436 varied in order to get the drug release to the extent desired (to reach the therapeutic levels) or to 437 obtain the minimum inhibitory concentration. As a summary from the results obtained from drug 438 release studies, the nanocellulose reinforced chitosan/Tween 20 hydrogel can be suggested as a 439 promising candidate for carrying curcumin for the absorption of stomach and upper intestinal 440 tract.

441 3.3.2.2. Drug release from gas foamed hydrogel

442 Fig. 7b has clearly illustrates that nanocellulose reinforced chitosan hydrogel fabricated using 443 carbon dioxide gas foaming process possess large-scale macroporous with wide interconnected 444 pores and large accessible surface area. Due to the large pore size of hydrogels, a rapid initial 445 burst release of drug was typically observed as observed in previous study [8].

446 Fig. 10. Curcumin release from gas foamed hydrogel and hydrogels formed at atmospheric 447 condition with different concentrations of Tween 20.

448 As shown in Fig. 10, the concentration of released drug from gas foamed hydrogel was greater 449 when compared to the hydrogel formed at atmospheric condition within the first 120 minutes. 450 The increased pore size and pore interconnectivity of gas foamed hydrogel act as a capillary 451 system causing a rapid diffusion of drug solution through the hydrogel matrix [50]. At 60 452 minutes, For the hydrogel containing 5\%(w/v) Tween 20, the cumulative release of drug at 45360 minutes was $8.51 \% \pm 0.61 \%$ and $7.95 \% \pm 0.39 \%$ for gas foamed hydrogel and hydrogel 
454 formed at atmospheric condition respectively. While, the cumulative release of drug at 60 455 minutes was $21.58 \% \pm 0.32 \%$ and $20.87 \% \pm 0.46 \%$ respectively for hydrogel containing $30 \%$ $456(\mathrm{w} / \mathrm{v})$ Tween 20 prepared under gas foam and at atmospheric condition. After the burst 457 release, the rate of drug release of both types of hydrogels become almost similar.

458 From our previous study [8], the gas foamed hydrogel showed higher drug release when 459 compared to the hydrogel formed at atmospheric condition. However, gas foamed hydrogel 460 did not show any improvement of the drug release over the hydrogel formed at atmospheric 461 condition in this study. Kawase, Michibayashi, Nakashima, Kurikawa, Yagi and Mizoguchi 462 [51] reported that the permeation rates of the drug from post-loaded formulations are 463 generally more rapid compared to the in situ loaded ones. This may be due to drug being 464 deposited in microporous spaces of the hydrogel when post-loaded instead of being embedded 465 within polymeric network when loaded in situ. In our previous study by applying post-loading 466 method, gas foamed hydrogel with large and interconnected pore structures has allowed the 467 drug deposited in the pore spaces of the hydrogel to be easily transported [52]. Therefore, the 468 prepared gas foamed hydrogel with post-loading method has attributed to higher drug release 469 compared to the hydrogel prepared at atmospheric condition in the previous study [8].

470 In the current research work, we have applied in situ loading method for the drug loading. The 471 gas foamed hydrogel with larger interconnected pore structures would cause less impact on 472 the drug release from the in situ loaded formulations [44, 45, 52]. Therefore, the gas foamed 473 hydrogel did not show any improvement of the drug release over the hydrogel formed at 474 atmospheric condition in this study.

475 3.4. Drug activity 
476 The chemical reactivity and biological activity of the drug are the most critical parameters in

477 drug delivery systems after drug release process [30]. Curcumin has three reactive functional

478 groups which associated with its different biological activities: one diketone moiety, and two

479 phenolic groups. The presence of $\mathrm{C}=\mathrm{O}$ groups as hydrogen acceptors and $\mathrm{C}-4$ as a hydrogen

480 donor are the important chemical reactions associated with its biological activities [53-54].

481 Fig. 11. UV-visible spectra of (a) pure drug and (b) released drug.

482 As shown in Fig. 11a and 11b, both of the UV-visible spectra indicate absorption peak around $483427 \mathrm{~nm}$. This can be assigned to the low-energy $\pi$ - $\pi^{*}$ excitation of the chromophore which 484 formed due to the enolization of the diketone group and conjugation between the $\pi$-electron 485 clouds of the two vinylguaiacol [31]. The presence of the absorption peak around $427 \mathrm{~nm}$ in both 486 of the spectra revealed that the reactive functional groups which associated with the biological 487 activity of curcumin retained without any deterioration due to any denaturation reaction with the 488 carrier molecules.

489 3.5. Solubility study

490 From our previous study [8,10], we observed lower drug release profiles of the hydrogel due to 491 poor solubility of curcumin in simulated gastric fluid. To improve curcumin's solubility, Tween 49220 was selected as potential solubilizing agent due to its biocompatibility and previous 493 successful application in curcumin drug delivery systems [16, 17, 55].

494 Fig. 12. Solubility of curcumin in simulated gastric fluid with different concentrations of Tween 49520. 
496 The ability of Tween 20 to solubilize curcumin in simulated gastric fluid was evaluated by 497 measuring the curcumin concentration in curcumin-saturated simulated gastric fluid with various 498 amounts of Tween 20. As shown in Fig. 12, the solubility of the drug gradually increased with 499 increasing the concentration of nonionic surfactant (Tween 20), with an upper limit of $3.014 \pm$ $500 \quad 0.041 \mathrm{mg} / \mathrm{mL}$ in the presence of $3.2 \%(\mathrm{w} / \mathrm{v})$ Tween 20 . Similar results were obtained from the 501 studies on solubility of curcumin in aqueous polysorbate micelle reported by Inchai, Ezure, 502 Hongwiset and Yotsawimonwat [56]. Their studies had showed that the solubility of curcumin 503 increased up to $2.7 \mathrm{mg} / \mathrm{mL}$ in $20 \%$ aqueous solution of Tween 20. O'Toole, Henderson, Soucy, 504 Fasciotto, Hoblitzell, Keynton, Ehringer and Gobin [17] showed that the saturation point of 505 curcumin increased linearly with increasing the Tween 20 concentration in $1 \%$ acetic acid 506 medium. Their findings revealed that the solubility of curcumin increased to an upper limit of $507294 \mu \mathrm{M}(\sim 0.108 \mathrm{mg} / \mathrm{L})$ with $0.05 \%(\mathrm{w} / \mathrm{v})$ Tween 20.

508 With higher $\mathrm{pH}$, curcumin degrades rapidly (on the timescale of minutes). However, the 509 solubility of curcumin decreases rapidly with decreasing of $\mathrm{pH}$ [56-57]. In our study, the 510 solubility of curcumin in simulated gastric medium was $\sim 6 \mu \mathrm{g} / \mathrm{mL}$ (without addition of the 511 surfactant). It showed a slight decrease when compared to the results obtained by Hung, Chen, 512 Lee, Sun, Lee and Huang [58] which was $25 \mu \mathrm{M}(\sim 9.2 \mu \mathrm{g} / \mathrm{mL})$ in $\mathrm{pH} 7$ buffer solution. This 513 may be due to the low $\mathrm{pH}$ of the simulated gastric fluid.

\section{4. Conclusions}

515 In this study, curcumin was extracted from dried rhizomes of curcuma longa using methanol for 516 preparation of curcumin loaded chitosan/nanocellulose/Tween20 hydrogel. As a result of low517 energy $\pi-\pi^{*}$ excitation of the chromophore, both curcumin (HIMEDIA Co.) and curcumin 
518 (extracted) showed typical absorption peaks around $420 \mathrm{~nm}$ in the UV-visible spectrum. The

519 drug release of the hydrogel increased from $0.21 \% \pm 0.02 \%$ to $54.85 \% \pm 0.77 \%$ with increasing 520 of Tween 20 concentration from $0 \%$ to $30 \%(\mathrm{w} / \mathrm{v})$ after $7.5 \mathrm{~h}$ immersion. FESEM micrographs 521 had proven that the pore size of the hydrogel increased more than tenfold after the gas foaming 522 process (at 50 bar). Gas foamed hydrogel showed a high burst release of the drug compared to 523 the hydrogel formed at atmospheric condition. The entrapment efficiency of the hydrogels 524 decreased with increasing the Tween 20 concentration. Solubility studies showed that the 525 saturation point of curcumin increased linearly with increasing the concentration of nonionic 526 surfactant (Tween 20). The mavimum limit of $3.014 \pm 0.041 \mathrm{mg} / \mathrm{mL}$ was achieved with the 527 introduction of $3.2 \%(\mathrm{w} / \mathrm{v})$ of Tween 20 . Furthermore, curcumin retained its structural integrity 528 after release to the gastric medium, which is a critical requirement for preserving drug activity. 529 The solubility of a drug is a fundamental parameter in terms of promoting any effect impacting 530 the therapeutic effect of the drug. Thus, the Tween 20 incorporated chitosan/nanocellulose 531 hydrogel has provided promising platform as a carrier for curcumin with improved solubility 532 characteristics for the absorption from stomach and upper intestinal tract. Since biocompatibility 533 of the hydrogel system is a critical concern for researchers in drug delivery field. Therefore, 534 investigations on the cytotoxicity and biocompatibility of the Tween 20 incorporated 535 chitosan/nanocellulose hydrogel for in vivo drug delivery applications will be conducted in 536 future works.

Acknowledgments: The authors would like to acknowledge the financial support from the 538 Ministry of Education Malaysia: FP053-2015A and PR005-2017A; and University Malaya 539 research grant: PG160-2016A, RU005D-2016, and ST012-2017 and RU018I-2016 and 540 International Funding AUA Scholars IF025-2018 for the success of this project. 


\section{References}

550 [1] D. Madhavi, D. Kagan, Bioavailability of a sustained release formulation of curcumin, 551 Integrative Medicine: A Clinician's Journal 13(3) (2014) 24.

552 [2] S. Zorofchian Moghadamtousi, H. Abdul Kadir, P. Hassandarvish, H. Tajik, S. Abubakar, K. 553 Zandi, A review on antibacterial, antiviral, and antifungal activity of curcumin, BioMed research 554 international 2014 (2014).

555 [3] R. De, P. Kundu, S. Swarnakar, T. Ramamurthy, A. Chowdhury, G.B. Nair, A.K. 556 Mukhopadhyay, Antimicrobial activity of curcumin against Helicobacter pylori isolates from 557 India and during infections in mice, Antimicrobial agents and chemotherapy 53(4) (2009) 15925581597.

559 [4] G. Mahady, S. Pendland, G. Yun, Z. Lu, Turmeric (Curcuma longa) and curcumin inhibit the 560 growth of Helicobacter pylori, a group 1 carcinogen, Anticancer research 22(6C) (2002) 41795614181.

562 [5] N.A. Mohammed, N.Y. Habil, Evaluation of antimicrobial activity of curcumin against two 563 oral bacteria, Automation, Control and Intelligent Systems 3(2-1) (2015) 18-21.

564 [6] A. Petchsomrit, N. Sermkaew, R. Wiwattanapatapee, Alginate-based composite sponges as 565 gastroretentive carriers for curcumin-loaded self-microemulsifying drug delivery systems, 566 Scientia pharmaceutica 85(1) (2017) 11.

567 [7] P. Ratanajiajaroen, M. Ohshima, Synthesis, release ability and bioactivity evaluation of chitin 568 beads incorporated with curcumin for drug delivery applications, Journal of microencapsulation $56929(6)(2012) 549-558$.

570 [8] T.M.S. Udeni Gunathilake, Y.C. Ching, C.H. Chuah, Enhancement of curcumin 571 bioavailability using nanocellulose reinforced chitosan hydrogel, Polymers 9(2) (2017) 64.

572 [9] Y.C. Ching, A. Ershad, C.A. Luqman, K.W. Choo, C.K. Yong, J.J. Sabariah, C.H. Chuah, 573 N.S. Liou, Rheological properties of cellulose nanocrystal-embedded polymer composites: A 574 review. Cellulose 23 (2016) 1011-1030. 
[10] U.T.M. Sampath, Y.C. Ching, C.H. Chuah, R. Singh, P.-C. Lin, Preparation and characterization of nanocellulose reinforced semi-interpenetrating polymer network of chitosan hydrogel, Cellulose 24(5) (2017) 2215-2228.

578 [11] K.W.Choo, Y.C. Ching, C.H. Chuah, J. Sabariah, N.S. Liou, Preparation and 579 characterization of polyvinyl alcohol-chitosan composite films reinforced with cellulose 580 nanofiber, Materials 9 (8 (2016) 644. [12] J. Lu, X. Li, R. Yang, J. Zhao, Y. Qu, Tween 40 pretreatment of unwashed water-insoluble solids of reed straw and corn stover pretreated with liquid hot water to obtain high concentrations of bioethanol, Biotechnology for biofuels 6(1) (2013) 159. [13] M.S. El-Ridy, A. Abdelbary, T. Essam, R.M. Abd EL-Salam, A.A. Aly Kassem, Niosomes as a potential drug delivery system for increasing the efficacy and safety of nystatin, Drug development and industrial pharmacy 37(12) (2011) 1491-1508. [14] A. Abdelbary, T. Essam, R. Abd El-Salam, A. AlyKassem, Niosomes as a potential drug delivery system for increasing the efficacy and safety of nystatin (antifungal), Drug Dev Ind Pharm 37 (2011) 149-508.

[15] S. Mehta, G. Kaur, K. Bhasin, Tween-embedded microemulsions-physicochemical and spectroscopic analysis for antitubercular drugs, AAPS PharmSciTech 11(1) (2010) 143-153. [16] P. Ratanajiajaroen, A. Watthanaphanit, H. Tamura, S. Tokura, R. Rujiravanit, Release characteristic and stability of curcumin incorporated in $\beta$-chitin non-woven fibrous sheet using Tween 20 as an emulsifier, European Polymer Journal 48(3) (2012) 512-523. [17] M.G. O’Toole, R.M. Henderson, P.A. Soucy, B.H. Fasciotto, P.J. Hoblitzell, R.S. Keynton, W.D. Ehringer, A.S. Gobin, Curcumin encapsulation in submicrometer spray-dried chitosan/Tween 20 particles, Biomacromolecules 13(8) (2012) 2309-2314. physical properties of oil entrapped alginate bead formulation of curcumin, International Journal of Medical, Health, Biomedical, Bioengineering and Pharmaceutical Engineering 7(12) (2013) 864-868.

602

603

[19] T. Cserháti, E. Forgács, G. Oros, Biological activity and environmental impact of anionic surfactants, Environment international 28(5) (2002) 337-348.

604 [20] A.A.H. Sathali, G. Rajalakshmi, Evaluation of transdermal targeted niosomal drug delivery 605

606

607

608

609

610

611

612

613

614 of terbinafine hydrochloride, Int J Pharm Tech Res 2(3) (2010) 2081-2089.

[21] K. Prabhakar, S.M. Afzal, G. Surender, V. Kishan, Tween 80 containing lipid nanoemulsions for delivery of indinavir to brain, Acta Pharmaceutica Sinica B 3(5) (2013) 345353.

[22] A. Petchsomrit, N. Sermkaew, R. Wiwattanapatapee, Effect of alginate and surfactant on physical properties of oil entrapped alginate bead formulation of curcumin, World Academy of Science, Engineering and Technology, International Journal of Medical, Health, Biomedical, Bioengineering and Pharmaceutical Engineering 7(12) (2013) 864-868.

[23] T. Ren, N. Xu, C. Cao, W. Yuan, X. Yu, J. Chen, J. Ren, Preparation and therapeutic efficacy of polysorbate-80-coated amphotericin B/PLA-b-PEG nanoparticles, Journal of Biomaterials Science, Polymer Edition 20(10) (2009) 1369-1380. 617 S.A. Rizvi, Influence of polymer ratio and surfactants on controlled drug release from cellulosic 618 microsponges, International journal of biological macromolecules (2017).

619 [25] M.S. Baig, A. Ahad, M. Aslam, S.S. Imam, M. Aqil, A. Ali, Application of Box-Behnken 620 design for preparation of levofloxacin-loaded stearic acid solid lipid nanoparticles for ocular 
delivery: Optimization, in vitro release, ocular tolerance, and antibacterial activity, International journal of biological macromolecules 85 (2016) 258-270. [26] C.S.F. Picone, R.L. Cunha, Formation of nano and microstructures by polysorbate-chitosan association, Colloids and Surfaces A: Physicochemical and Engineering Aspects 418 (2013) 2938.

[27] D. Jansirani, R. Saradha, N. Salomideborani, J. Selvapriyadharshini, Comparative evaluation of various extraction methods of curcuminoids from Curcuma longa, Journal of Chemical and Pharmaceutical Sciences (4) (2014) 286-288.

[28] A.L. Parize, H.K. Stulzer, M.C.M. Laranjeira, I.M.d.C. Brighente, T.C.R.d. Souza, Evaluation of chitosan microparticles containing curcumin and crosslinked with sodium tripolyphosphate produced by spray drying, Química Nova 35(6) (2012) 1127-1132. [29] S. Li, X. Lin, K. Xu, J. He, H. Yang, H. Li, Co-grinding effect on crystalline zaltoprofen with $\beta$-cyclodextrin/cucurbit [7] uril in tablet formulation, Scientific Reports 7 (2017).

634 [30] S. Bashir, Y.Y. Teo, S. Ramesh, K. Ramesh, Synthesis, characterization, properties of Nsuccinyl chitosan-g-poly (methacrylic acid) hydrogels and in vitro release of theophylline, Polymer 92 (2016) 36-49.

637

638

639

[31] F. Zsila, Z. Bikádi, M. Simonyi, Circular dichroism spectroscopic studies reveal $\mathrm{pH}$ dependent binding of curcumin in the minor groove of natural and synthetic nucleic acids, Organic \& biomolecular chemistry 2(20) (2004) 2902-2910.

640

641

642

643

[32] R. Fugita, D. Gálico, R. Guerra, G. Perpétuo, O. Treu-Filho, M. Galhiane, R. Mendes, G. Bannach, Thermal behaviour of curcumin, Braz J Therm Anal 1 (2012) 19-23.

[33] V.T. Bich, N.T. Thuy, N.T. Binh, N.T.M. Huong, P.N.D. Yen, T.T. Luong, Structural and spectral properties of curcumin and metal-curcumin complex derived from turmeric (Curcuma longa), Physics and engineering of new materials (2009) 271-278.

644

645

[34] T.M. Kolev, E.A. Velcheva, B.A. Stamboliyska, M. Spiteller, DFT and experimental studies of the structure and vibrational spectra of curcumin, International Journal of Quantum Chemistry 102(6) (2005) 1069-1079.

648 [35] P.K. Mohan, G. Sreelakshmi, C. Muraleedharan, R. Joseph, Water soluble complexes of 649 curcumin with cyclodextrins: Characterization by FT-Raman spectroscopy, Vibrational 650 Spectroscopy 62 (2012) 77-84.

651 [36] V. Rubentheren, T.A Ward, C.Y. Chee, P. Nair, Physical and chemical reinforcement of 652 chitosan film using nanocrystalline cellulose and tannic acid. Cellulose 22 (2015) 2529-2541.

653 [37] U.G. Sampath, Y.C. Ching, C.H. Chuah, J.J. Sabariah, P.-C. Lin, Fabrication of porous 654 materials from natural/synthetic biopolymers and their composites, Materials 9(12) (2016) 991.

[38] F. Dehghani, N. Annabi, Engineering porous scaffolds using gas-based techniques, Current opinion in biotechnology 22(5) (2011) 661-666.

[39] Z. Rahman, A.S. Zidan, M.J. Habib, M.A. Khan, Understanding the quality of protein loaded PLGA nanoparticles variability by Plackett-Burman design, International journal of pharmaceutics 389(1) (2010) 186-194.

[40] D. Ag Seleci, M. Seleci, J.-G. Walter, F. Stahl, T. Scheper, Niosomes as nanoparticular drug carriers: fundamentals and recent applications, Journal of Nanomaterials 2016 (2016).

[41] M. Nasr, S. Mansour, N.D. Mortada, A. Elshamy, Vesicular aceclofenac systems: a comparative study between liposomes and niosomes, Journal of Microencapsulation 25(7) 664 (2008) 499-512. 
[42] P.A. Bhat, A.A. Dar, G.M. Rather, Solubilization capabilities of some cationic, anionic, and nonionic surfactants toward the poorly water-soluble antibiotic drug erythromycin, Journal of Chemical \& Engineering Data 53(6) (2008) 1271-1277.

668 [43] Z.S. Bayindir, N. Yuksel, Characterization of niosomes prepared with various nonionic 669 surfactants for paclitaxel oral delivery, Journal of pharmaceutical sciences 99(4) (2010) 20492060. [44] R. Dinarvand, S. Moghadam, A. Sheikhi, F. Atyabi, Effect of surfactant HLB and different formulation variables on the properties of poly-D, L-lactide microspheres of naltrexone prepared by double emulsion technique, Journal of microencapsulation 22(2) (2005) 139-151.

[45] R.S.H. Wong, K. Dodou, Effect of drug loading method and drug physicochemical properties on the material and drug release properties of poly (ethylene oxide) hydrogels for transdermal delivery, Polymers 9(7) (2017) 286. [46] H.H. Tønnesen, J. Karlsen, Studies on curcumin and curcuminoids, Zeitschrift für Lebensmittel-Untersuchung und Forschung 180(5) (1985) 402-404.

[47] Y.W. Cho, J. Lee, S.C. Lee, K.M. Huh, K. Park, Hydrotropic agents for study of in vitro paclitaxel release from polymeric micelles, Journal of Controlled Release 97(2) (2004) 249-257. [48] S. Zang, T. Liu, J. Shi, L. Qiao, Curcumin: a promising agent targeting cancer stem cells, Anti-Cancer Agents in Medicinal Chemistry (Formerly Current Medicinal Chemistry-AntiCancer Agents) 14(6) (2014) 787-792.

683 [49] G. Liu, T. Xiang, Q.F. Wu, W.X. Wang, Curcumin suppresses the proliferation of gastric cancer cells by downregulating H19, Oncology letters 12(6) (2016) 5156-5162.

685

686

687

688

689

690

691

692

693

694

695

696

697

698

699

700

701

702

703

704

705

706

707

708

709 [50] T. M. S. Udenni Gunathilake, Y. C. Ching, K. Y. Ching, C. H. Chuah and L. Chuah Abdullah, Biomedical and microbiological applications of bio-Based porous materials: A review, Polymers 9 (160) (2017) 1-16.

[51] M. Kawase, N. Michibayashi, Y. Nakashima, N. Kurikawa, K. Yagi, T. Mizoguchi, Application of glutaraldehyde-crosslinked chitosan as a scaffold for hepatocyte attachment, Biological and Pharmaceutical Bulletin 20(6) (1997) 708-710.

[52] A. Ullah, C.M. Kim, G.M. Kim, Porous polymer coatings on metal microneedles for enhanced drug delivery, Royal Society open science 5(4) (2018) 171609.

[53] M. Ahmed, M.A. Qadir, M.I. Shafiq, M. Muddassar, A. Hameed, M.N. Arshad, A.M. Asiri, Curcumin: Synthesis optimization and in silico interaction with cyclin dependent kinase, Acta Pharmaceutica 67(3) (2017) 385-395.

[54] S. Wang, X. Liu, I.J. Villar-Garcia, R. Chen, Amino acid based hydrogels with dual responsiveness for oral drug delivery, Macromolecular bioscience 16(9) (2016) 1258-1264.

[55] A. Rahma, M.M. Munir, A. Prasetyo, V. Suendo, H. Rachmawati, Intermolecular interactions and the release pattern of electrospun curcumin-polyvinyl (pyrrolidone) fiber, Biological and Pharmaceutical Bulletin 39(2) (2016) 163-173.

[56] N. Inchai, Y. Ezure, D. Hongwiset, S. Yotsawimonwat, Investigation on solubility and stability of curcumin in aqueous polysorbate micelle, International Journal of Management and Applied Science (IJMAS) 3(4) (2015) 157-161.

[57] K. Fimantari, E. Budianto, Effect of drug loading method against drug dissolution mechanism of encapsulated amoxicillin trihydrate in matrix of semi-IPN chitosan-poly (Nvinylpyrrolidone) hydrogel with $\mathrm{KHCO} 3$ as pore forming agent in floating drug delivery system, AIP Conference Proceedings, AIP Publishing, 2018, p. 020001.

710 effect of curcumin, Biophysical journal 94(11) (2008) 4331-4338. 
1632

1633

1634

1635

1636

1637

1638

1639

1640

1641

1642

1643

1644

1645

1646

1647

1648

1649

1650

1651

1652

1653

1654

1655

1656

1657

1658

1659

1660

1661

1662

1663

1664

1665

1666

1667

1668

1669

1670

1671

1672

1673

1674

1675

1676

1677

1678

1679 


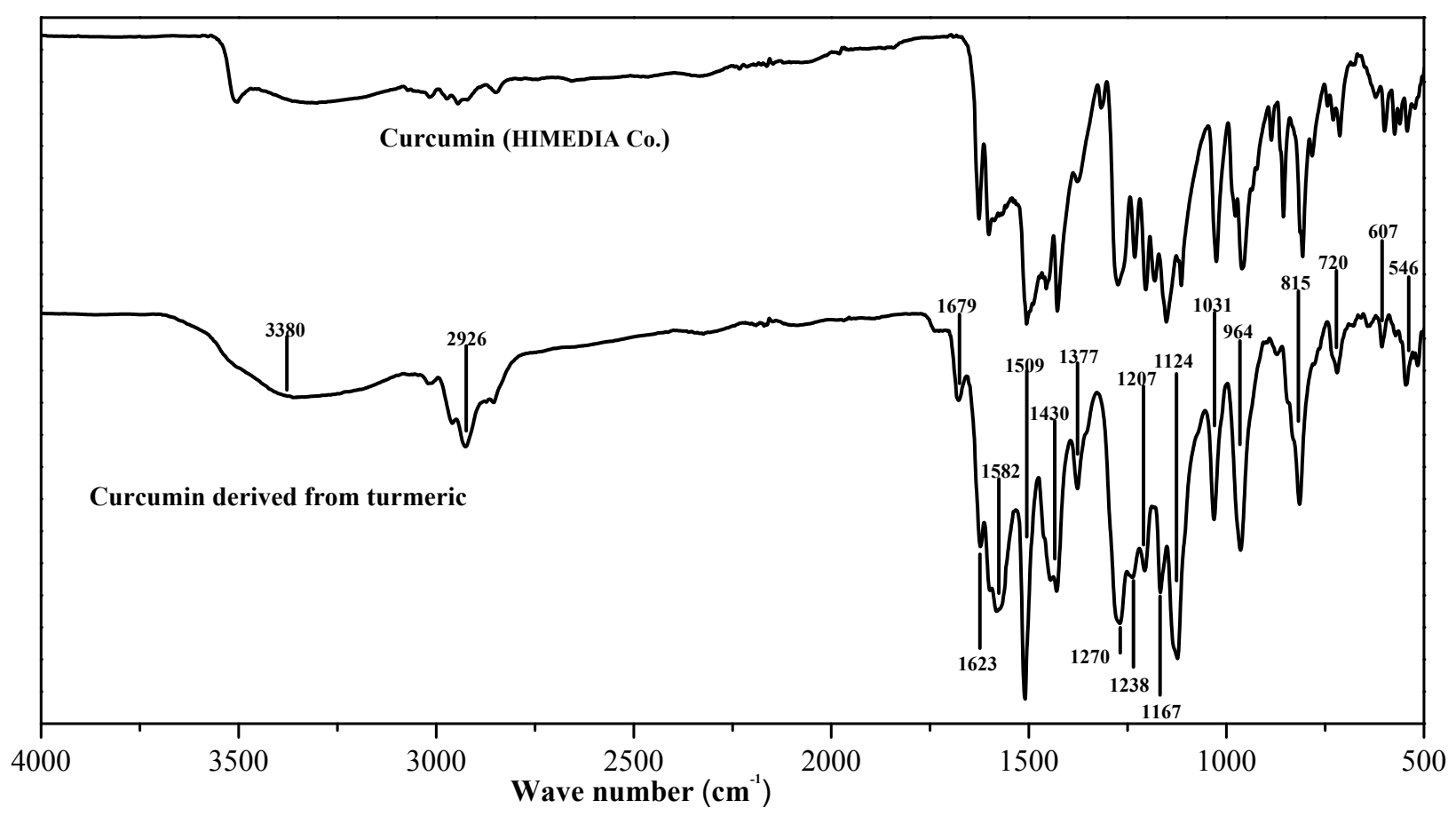

Fig. 1. FTIR spectra of curcumin (HIMEDIA Co.) and curcumin derived from turmeric. 
<smiles>COc1cc(/C=C/C(=O)CC(=O)/C=C/c2ccc(O)c(OC)c2)ccc1O</smiles><smiles>COc1cc(/C=C/C(=O)CC(=O)/C=C/c2ccc(O)cc2)ccc1O</smiles><smiles>O=C(/C=C/c1ccc(O)cc1)CC(=O)/C=C/c1ccc(O)cc1</smiles>

Bis-demethoxycurcumin

Fig. 2. Curcuminoids present in turmeric powder. 


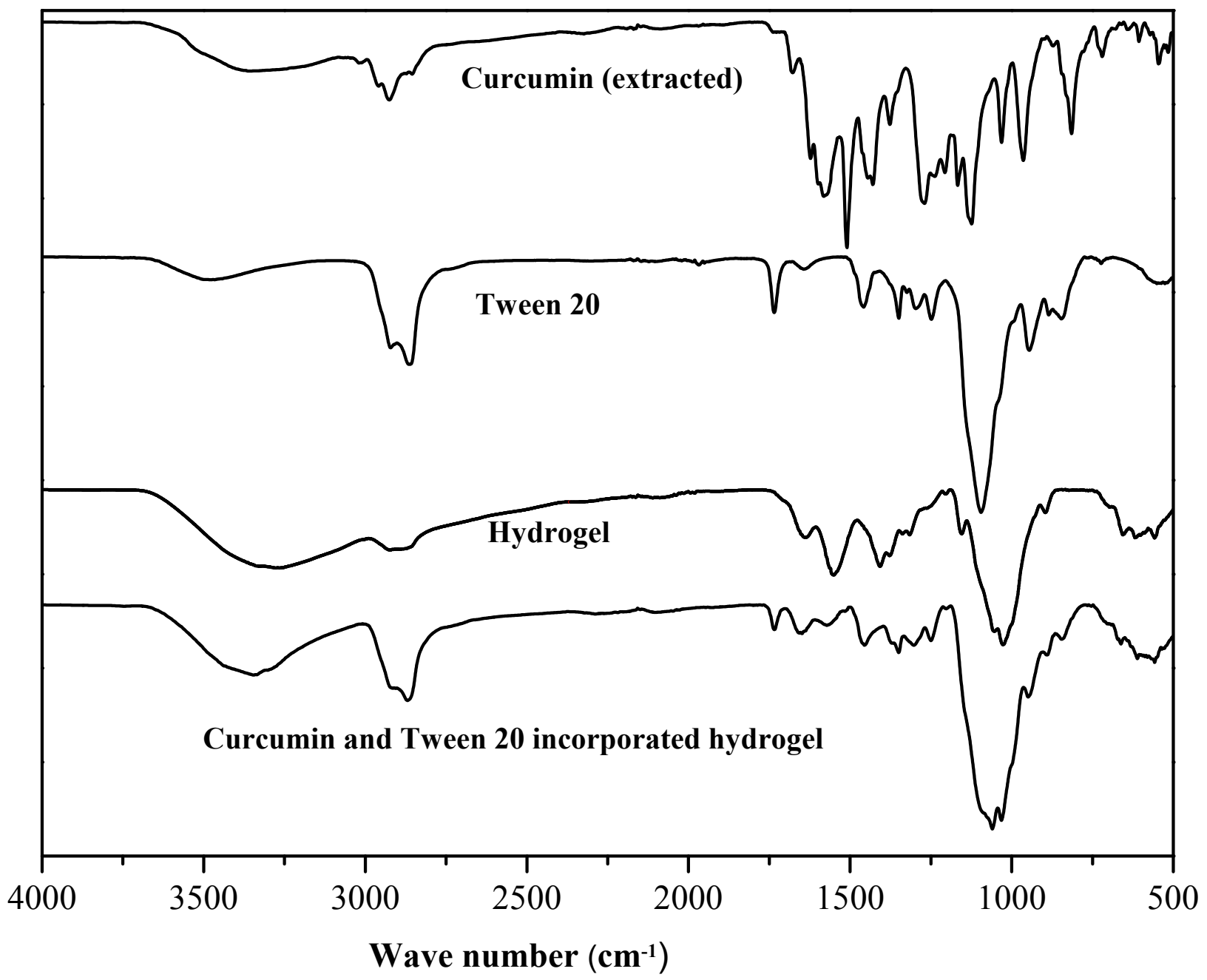

Fig. 3. FTIR spectra of curcumin (extracted), Tween 20, nanocellulose reinforced chitosan hydrogel and curcumin/Tween 20 incorporated hydrogel. 


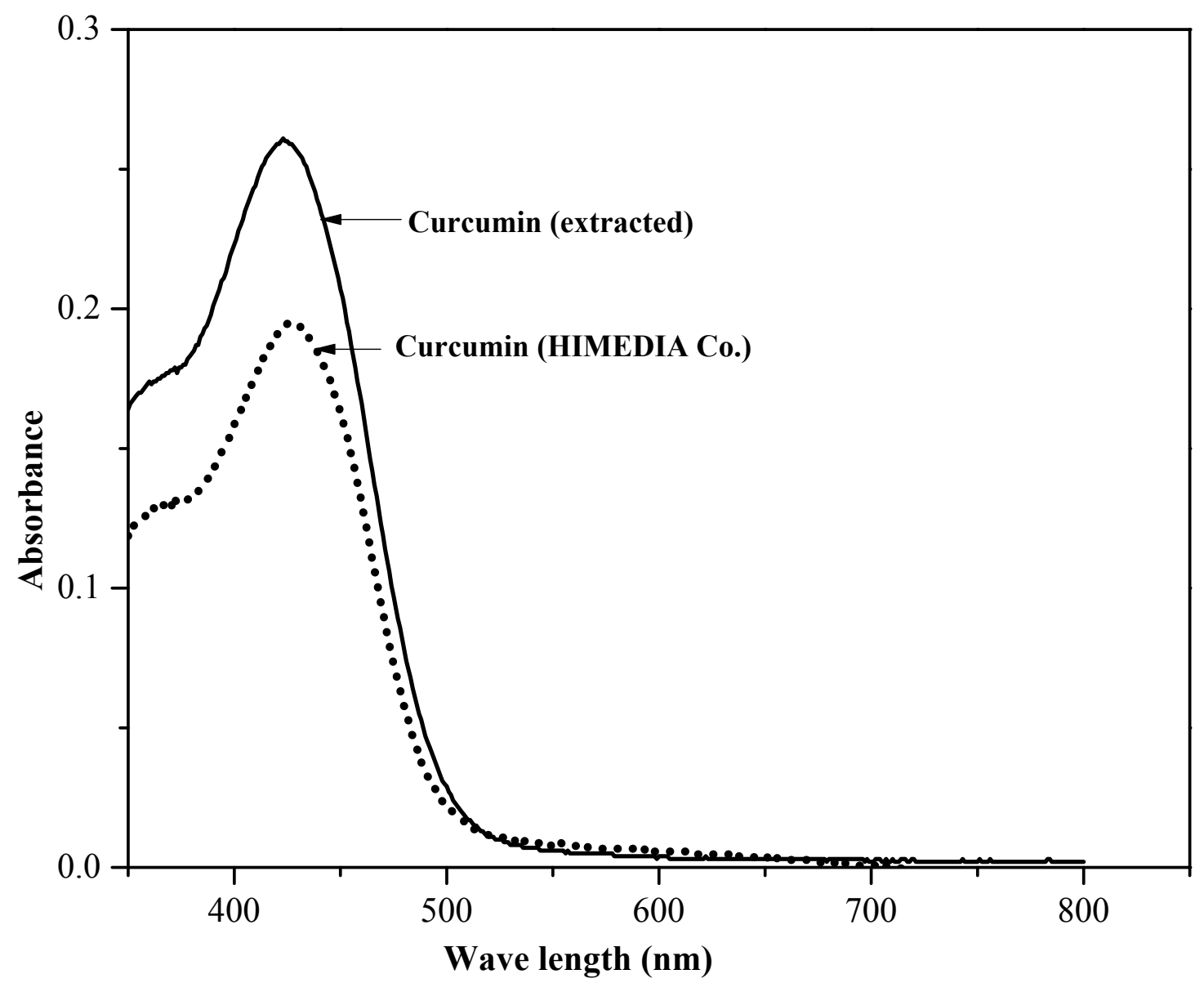

Fig. 4. UV-visible spectra of curcumin extracted from turmeric powder and curcumin (HIMEDIA Co.). 

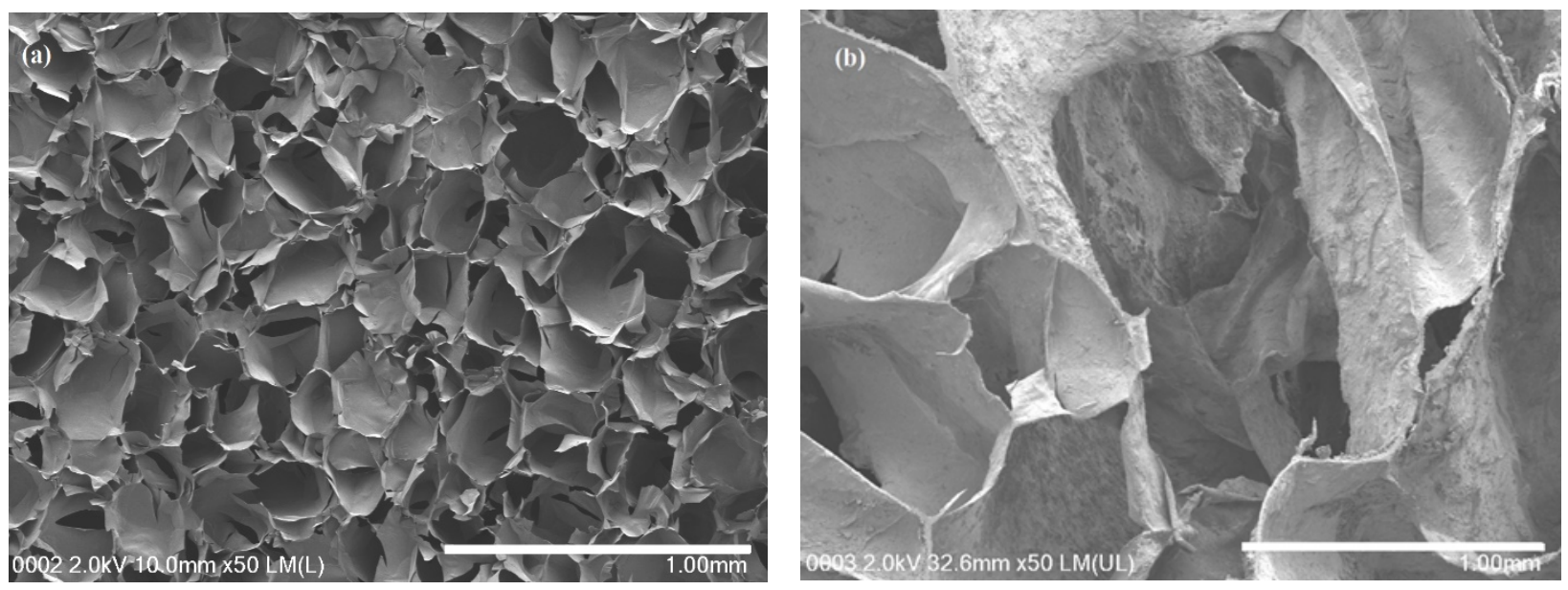

Fig. 5. Micrographs of a) hydrogel formed at atmospheric condition and b) gas foamed hydrogel. 


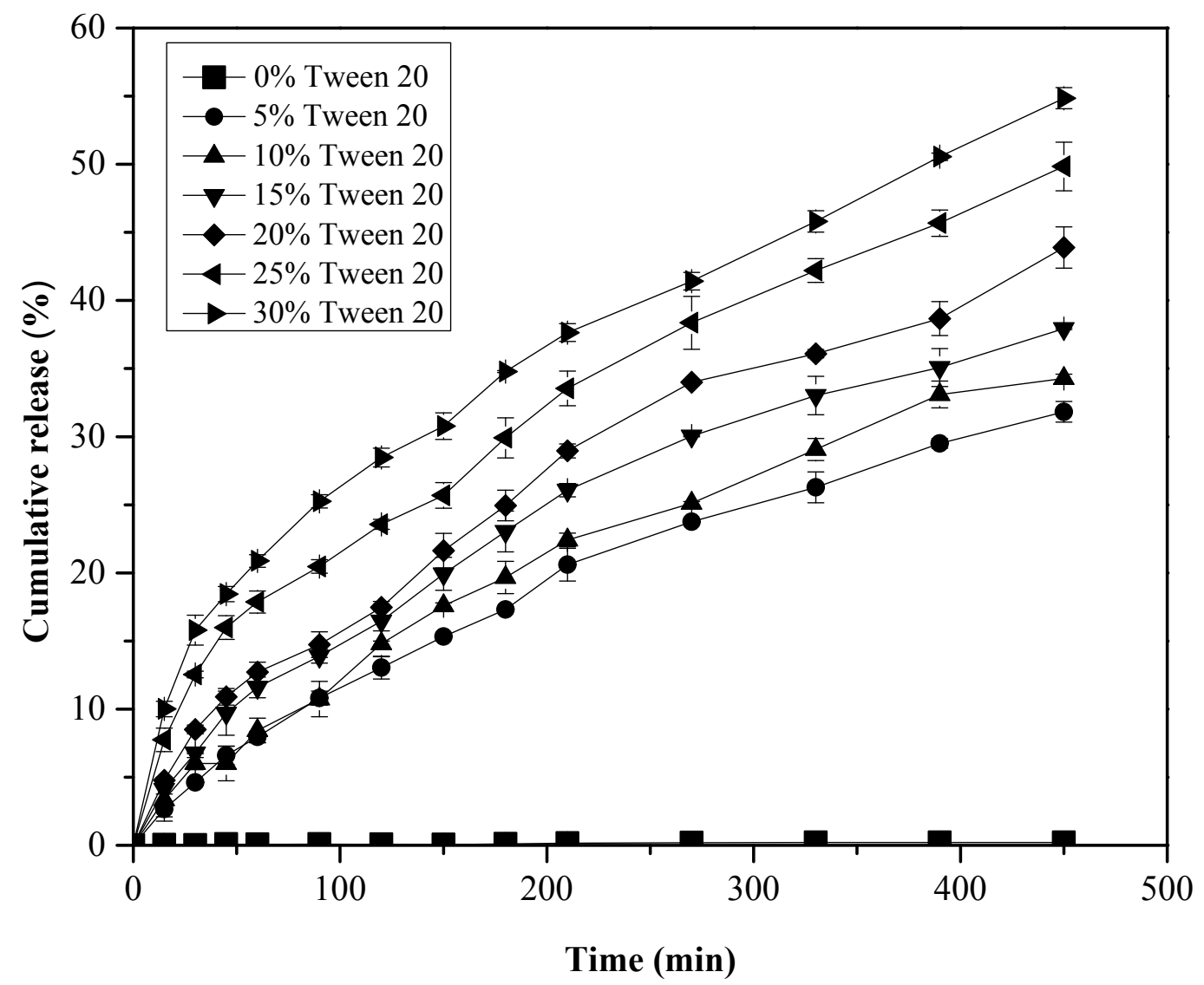

Fig. 6. Curcumin release from the hydrogels containing different concentrations of Tween 20 . 


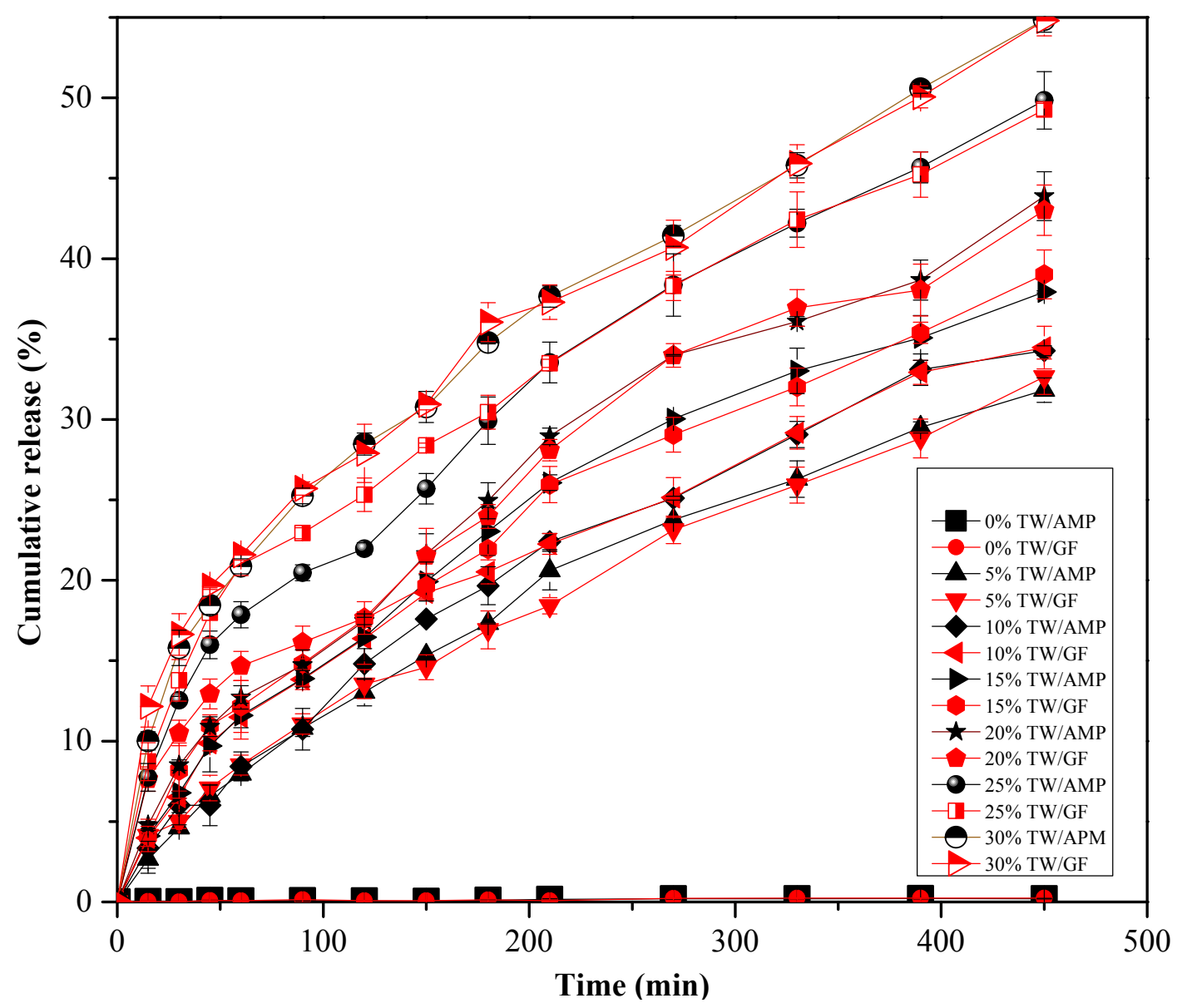

Fig. 7. Curcumin release from the hydrogels formed at atmospheric condition (AMP) and highpressure condition (GF) with different concentrations of Tween 20 (TW). 


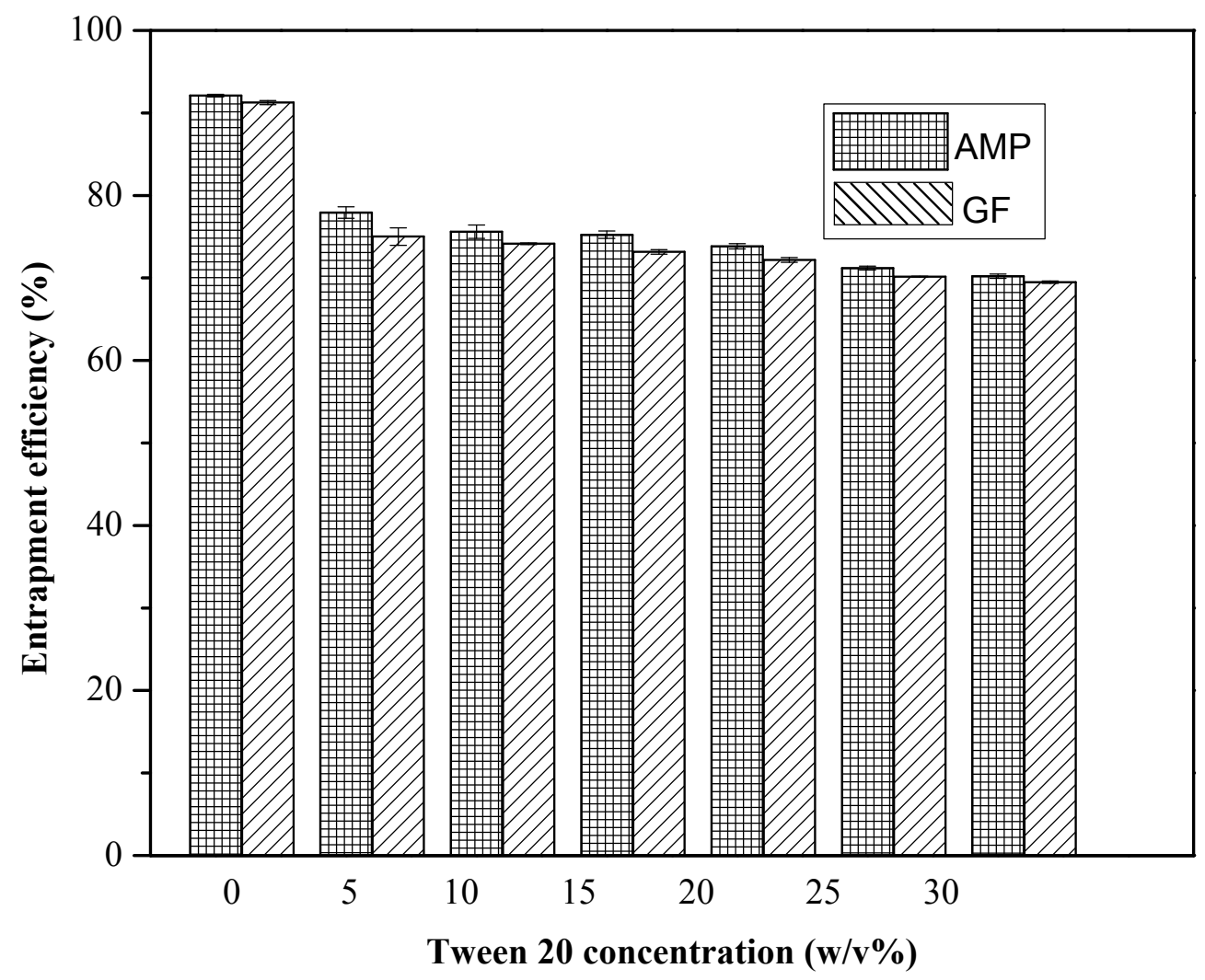

Fig. 8. Entrapment efficiency of curcumin in gas foamed hydrogel (GF) and hydrogel formed at atmospheric condition (AMP). 


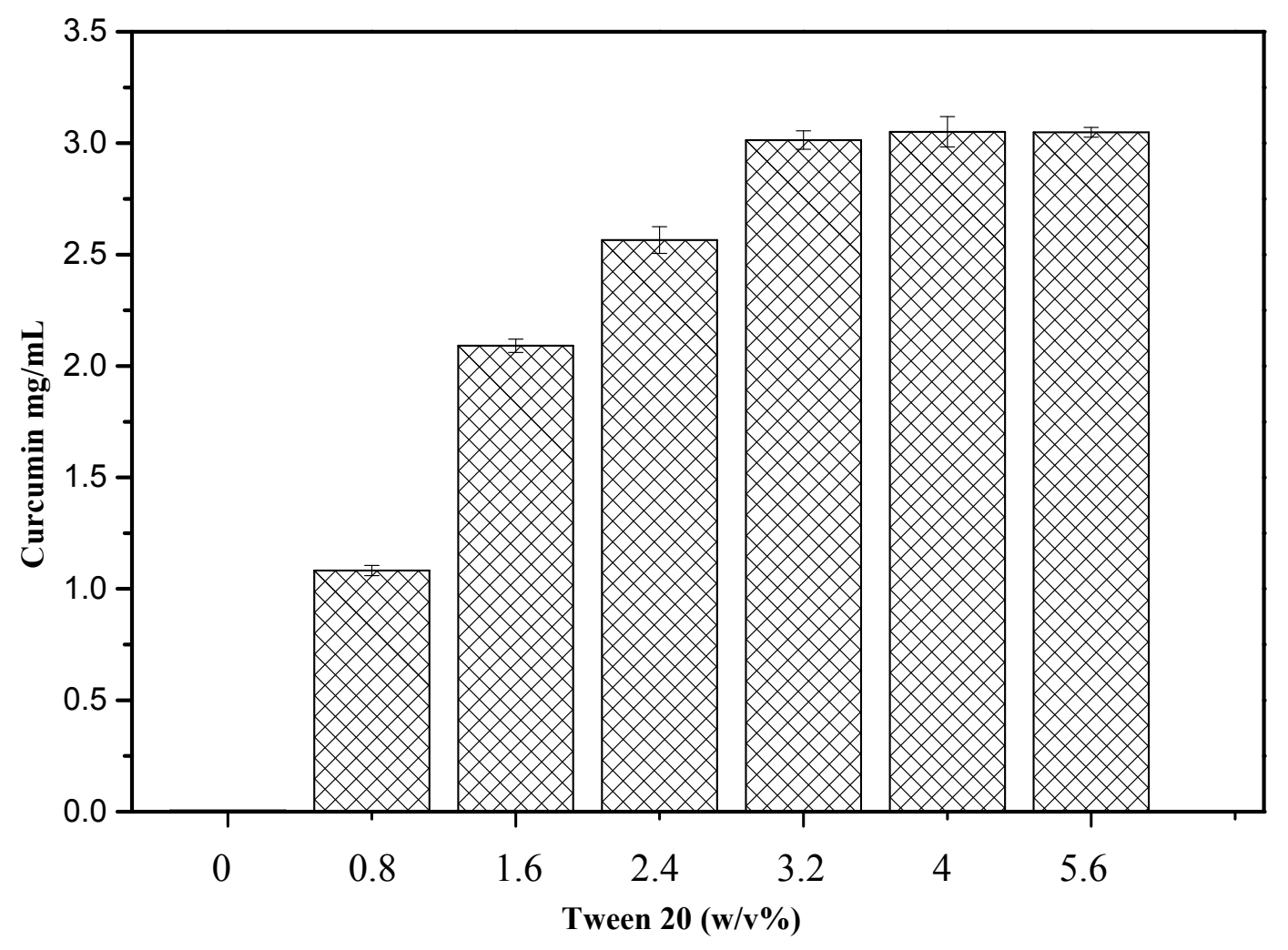

Fig. 9. Solubility of curcumin in simulated gastric fluid with different concentrations of Tween 20. 


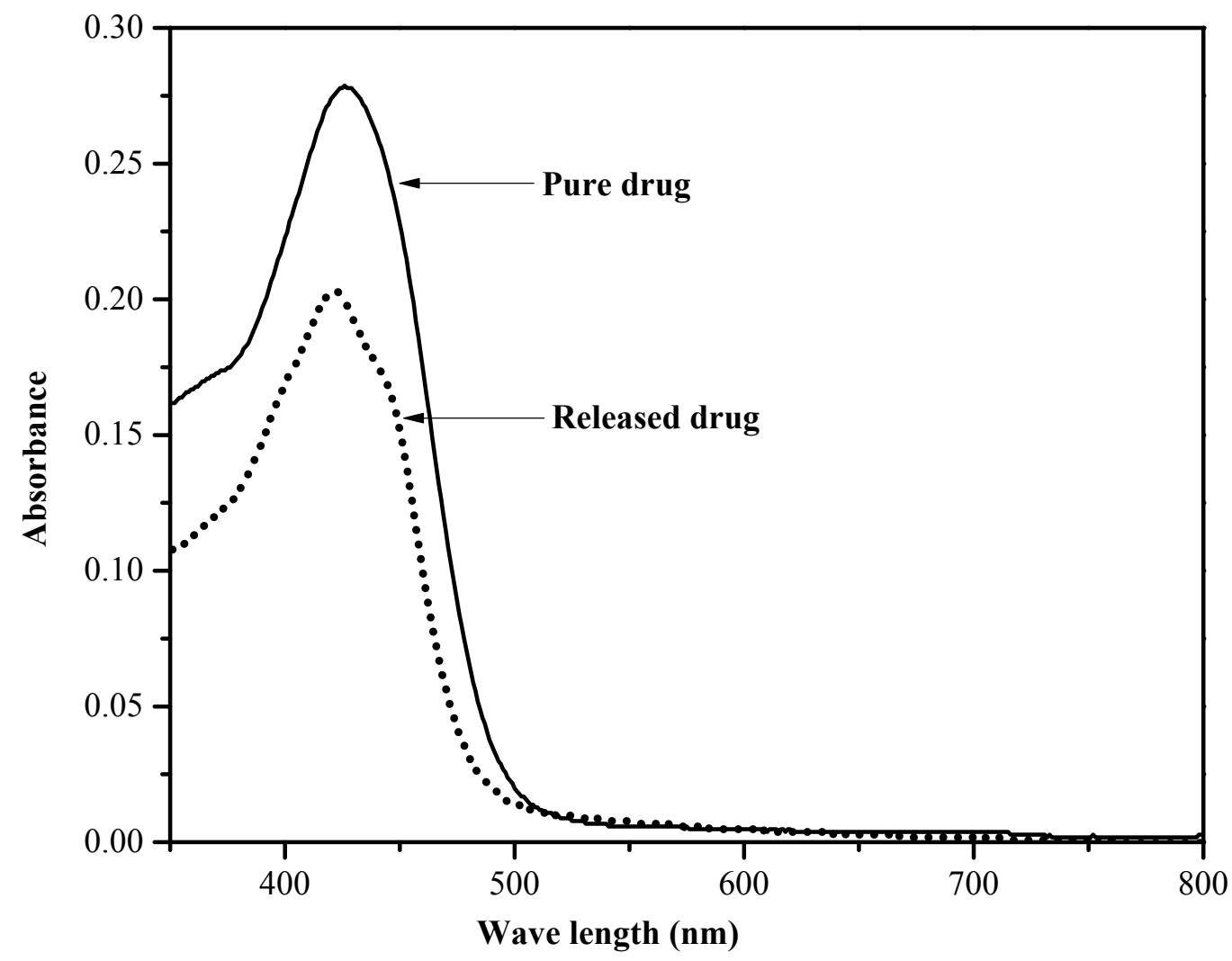

Fig. 10. UV-visible spectra of (a) pure drug and (b) released drug. 
Table 1.

Composition of curcumin entrapped chitosan/nanocellulose/Tween 20 hydrogel formulations.

\begin{tabular}{|c|c|c|c|c|c|}
\hline Formulation & $\begin{array}{l}\text { Chitosan } \\
(\mathrm{w} / \mathrm{v}) \%\end{array}$ & $\begin{array}{l}\text { Nanocellulose } \\
\qquad(\mathrm{w} / \mathrm{v}) \%\end{array}$ & $\begin{array}{c}\text { Tween } 20 \\
(\mathrm{w} / \mathrm{v}) \%\end{array}$ & $\begin{array}{l}\text { Glutaraldehyde } \\
\qquad(\mathrm{v} / \mathrm{v}) \%\end{array}$ & $\begin{array}{c}\text { Curcumin } \\
\text { (mg per } 2.5 \mathrm{~g} \text { of } \\
\text { hydrogel disc) }\end{array}$ \\
\hline $\mathrm{CH} / \mathrm{CNC} / \mathrm{TW}-0 \%$ & 2 & 0.5 & 0 & 0.2 & 1.5 \\
\hline $\mathrm{CH} / \mathrm{CNC} / \mathrm{TW}-5 \%$ & 2 & 0.5 & 5 & 0.2 & 1.5 \\
\hline $\mathrm{CH} / \mathrm{CNC} / \mathrm{TW}-10 \%$ & 2 & 0.5 & 10 & 0.2 & 1.5 \\
\hline $\mathrm{CH} / \mathrm{CNC} / \mathrm{TW}-15 \%$ & 2 & 0.5 & 15 & 0.2 & 1.5 \\
\hline $\mathrm{CH} / \mathrm{CNC} / \mathrm{TW}-20 \%$ & 2 & 0.5 & 20 & 0.2 & 1.5 \\
\hline $\mathrm{CH} / \mathrm{CNC} / \mathrm{TW}-25 \%$ & 2 & 0.5 & 25 & 0.2 & 1.5 \\
\hline $\mathrm{CH} / \mathrm{CNC} / \mathrm{TW}-30 \%$ & 2 & 0.5 & 30 & 0.2 & 1.5 \\
\hline
\end{tabular}

